Bolm Inst. oceanogr., S Paulo, 26:131-180, 1977

\title{
ESTUDO DAS VARIAÇ̃̃ES DA RELAÇÃO PESO TOTAL/COMPRIMENTO TOTAL EM FUNÇÃO DO CICLO REPRODUTIVO E COMPORTAMENTO, DE SARDINELLA BRASILIENSIS (STEINDACHNER, 1879) DA COSTA DO BRASIL ENTRE $23^{\circ} \mathrm{S}$ E $28^{\circ} \mathrm{S}^{*}$
}

\author{
CARMEN LUCIA DEL BIANCO ROSSI-WONGTSCHOWSKI**
}

Instituto Oceanográfico da Universidade de São Paulo

\section{SYNOPSIS}

This paper analyses some aspects on the length/weight relationship of Sardinella brasiliensis and its variations as a function of their reproductive cycle and displacements along the Brazilian coast between $23^{\circ} \mathrm{S}$ and $28^{\circ} \mathrm{S}$. The area surveyed was divided into five subareas, each one covering one degree of latitude. The relationship and its variations between shoals were studied for each sub-area at different seasons and for the sub-areas at the same season. The absence of a variation pattern for the length/weight relationship has shown to be the result of seasonal changes in the physiological aspects of fish (as a function of their reproductive cycle) as well as result of behaviour of individuals in two main areas: $23^{\circ} \mathrm{S}-25^{\circ} \mathrm{S}$ and $26^{\circ} \mathrm{S}-28^{\circ} \mathrm{S}$, which are spawning areas, spawning occuring during spring and summer at the first and only during spring at the latter. After spawning the young (from both areas) more at different times to a common trophic area where they find suitable conditions $\left(25^{\circ} \mathrm{S}-\right.$ $26^{\circ} \mathrm{S}$ ), returning to their original sub-areas at different occasions, following their first sexual maturation. Although spawning takes place at different times and sites, with the convergence of young to a common nursery, mixing might occur. Further studies on meristics and body proportions are being developed regarding the existence of different populations.

* Dissertação de mestrado apresentada ao Instituto de Biociências da Universidade de São Paulo.

** Bolsista da Fundação de Amparo à Pesquisa do Estado de São Paulo.

PUBL. NO 394 DO INST. OCEAN. DA USP. 


\section{NTRODUÇÃO}

0 presente estudo refere-se a análise da relação peso total/comprimento total, de Sardinella brasiliensis (Steindachner, 1879), da região da costa do Brasil compreendida entre as latitudes de $23^{\circ} \mathrm{S}$ e $28^{\circ} \mathrm{S}$, e de suas variações em função do ciclo reprodutivo e deslocamentos da espécie dentro da região considerada.

A procura de uma fórmula para expressar a relação peso/comprimento e prover meios de converter medidas de comprimento em peso (ou vice-versa), tem revelado complexidade entre as interrelações de peso, comprimento e fase de maturação sexual do peixe, tendo sido encontrada correlação entre suas variações e as mudanças sazonais no desenvolvimento gonadal.

Dados sobre peso e comprimento de peixes têm sido comumente analisados, como informação biológica, sob dois aspectos ou objetivos diferentes: 1) descrevendo matematicamente a relação, de tal modo que um elemento possa ser convertido no outro e 2) como medida da variação do peso esperado para o comprimento de um peixe ou grupos de indivíduos, indicando sua condição, ou seja, acúmulo de gordura, bem estar geral, desenvolvimento gonadal etc (Clark, 1928; Ramalho, 1936; Ananiades, 1951; Fairbridge, 1951; Le Cren, 1951; 0liver, 1951; Navaz \& Navarro, 1952; Schaeffer, 1952; Angelescu et al., 1958; Baxter, 1960; Val et al., 1962; Thomas, 1968; Nikolskii, 1969).

Adotou-se a terminologia empregada por Le Cren (1951), onde o termo "relação peso/comprimento" è aplicado rigorosamente ao primeiro aspecto acima citado, enquanto o termo "condição" é usado para anālise do segundo aspecto.

A relação peso/comprimento tem sido descrita para a maioria dos peixes através de uma expressão do tipo $W=a L^{b}$, onde $W$ é o peso total, L é o comprimento total, a uma constante e b um expoente que varia entre 2,5 e 4,0 (Hile, 1936; Martin, 1949; Hagerman, 1952; Schaeffer, 1952; Anadon, 1954; Nomura, 1962; Be11, 1964; Phillips, 1964; Thomas, 1968; Vanstone \& Market, 1968; Savitz, 1969).

Verifica-se que enquanto $b$ pode variar para peixes de localidades diversas, sexos distintos ou diferentes fases de crescimento, ele é geralmente constante para peixes em condições semelhantes dentro de cada um destes aspectos. A relação peso/comprimento pode portanto ser um carater de diferen- 
ciação para pequenas unidades taxonômicas, como o são as relações morfométricas (Clark, 1928; Le Gal1, 1930; Le Cren, 1951; MacGregor, 1959; Nagabhushanam, 1964; Humphreys, 1966; Heald \& Griffits, 1967; Jones, 1970; Botha, 1971; Vazzoler, 1971; Weatherley, 1972).

A fórmula que relaciona peso e comprimento, provê uma maneira para ca1cular o peso (W) a partir do comprimento (L), ou vice-versa, e é um caminho direto para converter em taxas de crescimento em peso, as taxas calculadas de crescimento em comprimento, podendo dar indicações de diferenças taxonômicas e eventos na história da vida do peixe tais como metamorfose e maturidade (Debrosses, 1933; Hickling, 1945; Andreu \& Rodrigues-Roda, 1951; Bas \& Morales, 1951; Le Cren, 1951; Muzinic, 1954).

Variações individuais da relação geral peso/comprimento têm sido usualmente consideradas mais interessantes que a própria relação em sí, e estudadas sob o nome geral de "condição"; mudanças na condição são estudadas por meio de um coeficiente de condição, um índice ponderal ou um fator de condição. Várias expressões foram utilizadas para estimar o fator de condição, sendo sua forma original a mais usada: $K=\frac{W}{L^{3}}$, onde $K \bar{e}$ o fator de condição, W o peso total e L o comprimento total do indivíduo (Clark, 1928; Hile, 1936).

Diferenças no fator de condição têm sido interpretadas como medidas de vārios eventos biológicos, tais como: variação da quantidade de gordura, suscetibilidade a mudanças do meio ambiente ou desenvolvimento gonadal (Clark, 1934; MacGregor, 1957; Blackburn, 1950; Fuster de Plaza \& Boschi, 1961; Vazzoler \& Vazzoler, 1965). Mudanças sazonais de tais eventos têm sido estudadas com a ajuda do fator de condição, mostrando que estão correlacionadas com ciclos gonadais, taxa de alimentação etc (Rudakova, 1959; Angelescu et al., 1958). Variações cíclicas curtas de crescimento alternado em peso e tamanho têm sido reveladas pelo uso do fator de condição (Brown, 1946; Fairbridge, 1951; Skud, 1955; Vanstone \& Market, 1968).

o estudo das sardinhas da costa do Brasil não tem obedecido a um planejamento racional, sendo que a maioria das afirmações e conclusões existentes necessitam comprovação com base em estudos mais detalhados. 
Aspectos gerais sobre a biologia da espécie foram tratados por Besnard (1950), Montes (1953), Furuya (1959), Richardson et al. (1959), Richardson \& Sadowski (1960), Moraes (1963), Watanabe (1963), Santos \& Frantzen (1965), Treme1 \& Jonsson (1965), Tremel et al. (1965), Vazzoler \& Vazzoler (1965), Treme1 (1967), Ito et al. (1969), Matsuura (1971), Vazzoler \& RossiWongtschowki (1976).

Existem vārias outras referências sobre a espécie, abrangendo temas gerais; entretanto, por carecerem de base científica sólida, deixamos de referi-1as.

Besnard (1950) analisou, em São Sebastião (São Paulo) a composição em comprimento de lotes de sardinhas jovens, sugerindo uma série de desovas consecutivas para a espécie, na região. Richardson et al. (1959) analisaram a pesca de Sardinella aurita na costa de Santos e Rio de Janeiro, e a composição em comprimento e idade dos desembarques no Rio e Santos, visando avaliar os estoques de sardinha e a influência da pesca sobre os mesmos. Richardson \& Sadowski (1960) analisaram a distribuição de comprimento de sardinhas jovens capturadas na região de Cananéia e estabeleceram uma correspondência entre os desembarques das mesmas em Cananéia, e os desembarques de sardinhas adultas no Rio de Janeiro, um ano mais tarde, sugerindo que a abundância de sardinhas jovens desembarcadas em Cananéia, em um ano, pode ser usada como indice de abundância de sardinhas grandes no ano seguinte, no Rio de Janeiro. Moraes (1963), a partir de dados de produção e esforço de pesca, procurou analisar as causas das variações de produção durante as várias épocas do ano, e de ano para ano. Santos \& Frantzen (1965) estimaram o crescimento da sardinha, analisando as distribuições de comprimento total durante o ano, utilizando-se de dados obtidos de amostras coletadas entre Ilha Grande e Santos. Furuya (1959) estudou a variação sazonal do teor de matéria graxa de sardinhas adquiridas no Mercado de Santos, sem informações quanto ao local de captura. Watanabe (1963) estudou a variação do conteúdo de lípides de sardinhas adultas, de Santos, durante o ano. Ito et al. (1969) estudando a variação sazonal da composição química da sardinha desembarcada em Santos em 1961, 1963, 1964 e 1966, encontraram resultados concordantes com os de Watanabe (1963). Vazzoler \& Vazzoler (1965) estabeleceram uma relação entre o fator de condição e o desenvolvimento sexual da sardinha. 
Matsuura (1971) analisando a distribuição de ovos e larvas na região entre Cabo Frio e Ilha de São Sebastião, confirmou as hipóteses levantadas por Richardson et al. (1959), Richardson \& Sadowski (1960), Moraes (1963) e Vazzoler \& Vazzoler (op. cit.) sobre a época e local de desova da sardinha.

No presente trabalho, através da anālise de aspectos referentes à relação peso/comprimento de Sardinella brasiliensis e suas variações entre cardumes, dentro e entre sub-äreas, dentro e entre estações do ano, e das mudanças sazonais no estado fisiológico e comportamento dos indivíduos, resultou uma visão global das interrelações e dependências entre a relação peso/comprimento e as variações do ciclo sazonal reprodutivo, deslocamento e aspectos alimentares, para a espécie, na região estudada.

Verificou-se que a inexistência de um padrão de variação da relação peso total/comprimento total para a espécie, nas diversas sub-áreas e estações do ano, está relacionada à entrada e saída de indivíduos em diferentes estádios de maturidade das e para as sub-āreas estudadas.

\section{MATERIAL E MÉTODO DE COLETA DOS DADOS}

Os dados utilizados para este estudo foram obtidos de exemplares de Sardinella brasiliensis coletados ao longo de toda a ärea compreendida entre $23^{\circ} \mathrm{S}$ e $28^{\circ} \mathrm{S}$, Brasil, entre agosto de 1970 e março de 1972.

A maioria dos exemplares foi coletada de barcos da frota comercial quando o local de operação da embarcação era bem definido e restrito; em áreas onde não havia operação dos mesmos, utilizou-se "tarrafa", pesca artesanal e capturas do N/Oc. "Prof. W. Besnard".

A área total, para melhor controle de coleta, foi subdividida em 5 subāreas: 1) Sub-ārea A $\left(23^{\circ} \mathrm{S}-24^{\circ} \mathrm{S}\right)$; 2) Sub-ārea B $\left(24^{\circ} \mathrm{S}-25^{\circ} \mathrm{S}\right)$; 3) Sub-ärea C $\left(25^{\circ} \mathrm{S}-26^{\circ} \mathrm{S}\right)$; 4) Sub-ärea D $\left(26^{\circ} \mathrm{S}-27^{\circ} \mathrm{S}\right)$ e 5) Sub-ärea E (27 $\left.{ }^{\circ} \mathrm{S}-28^{\circ} \mathrm{S}\right)$ (Fig. 1).

Foram realizadas amostragens periódicas de cardumes distintos, coletando-se 30 indivíduos de cada cardume. Os períodos escolhidos para amostragem foram as estações do ano, considerando-se: janeiro, fevereiro e março como VERÃO; abril, maio e junho como OUTONO; julho, agosto e setembro como INVERNO e outubro, novembro e dezembro como PRIMAVERA. 


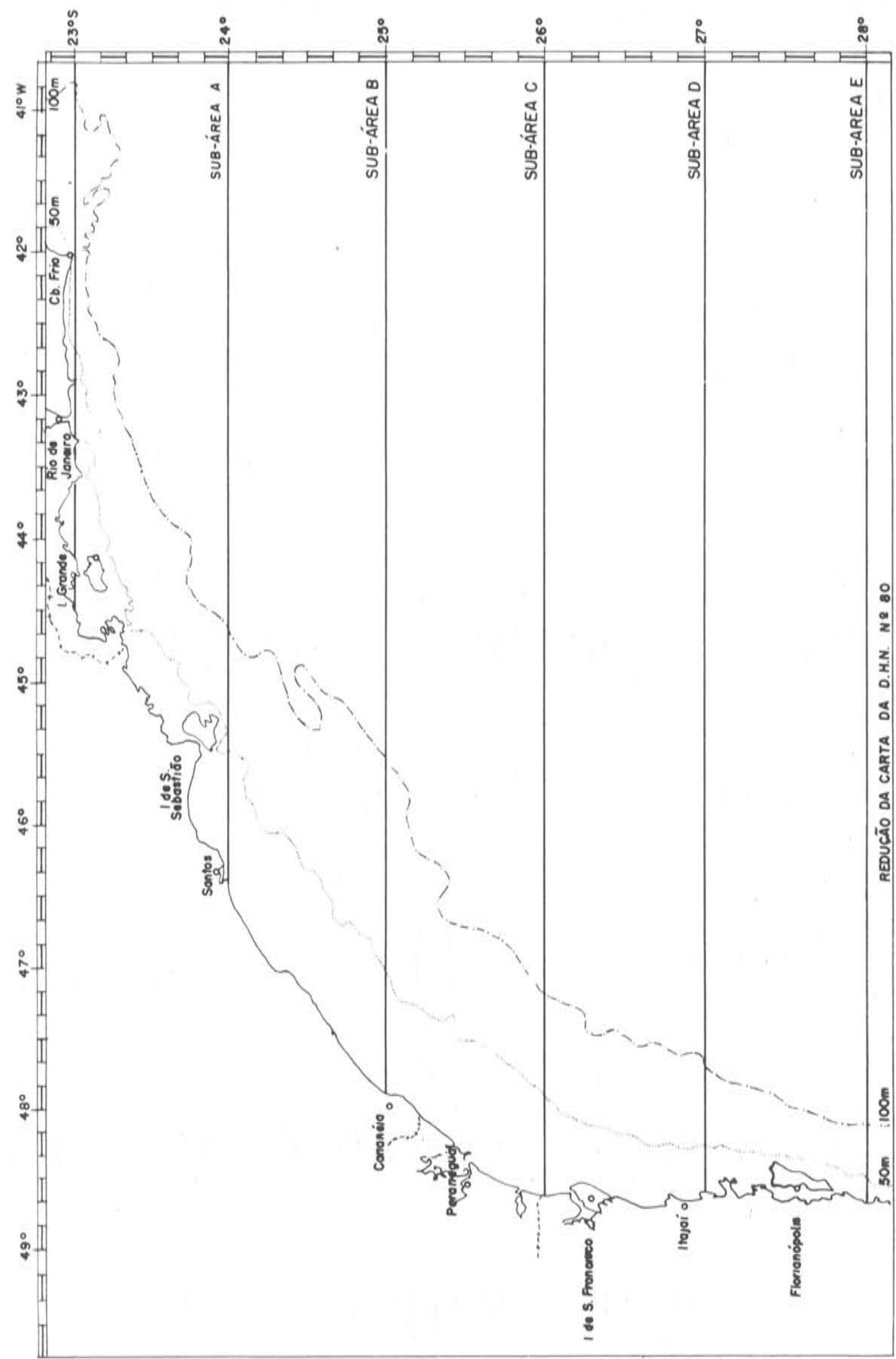

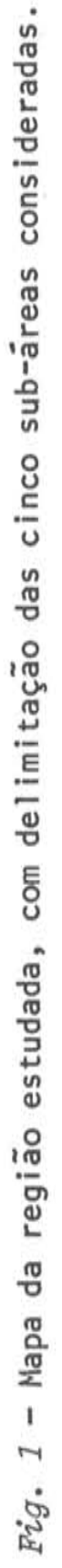


TABELA I - Lista das amostras de Sardinelza brasiliensis sobre as quais está baseado o presente estudo

\begin{tabular}{|c|c|c|c|c|c|c|}
\hline $\begin{array}{l}\text { NQ da } \\
\text { amostra }\end{array}$ & Local de coleta & Sub-ärea & $\begin{array}{c}\text { NQ de } \\
\text { exemplares }\end{array}$ & Estação do ano & Data de coleta & Aparelho de captura \\
\hline P1 & Entre Lage e Bertioga & B & 30 & Inverno & $27 / 08 / 70$ & Traina \\
\hline $\mathrm{P} 2$ & 8 wilhas para fora da Moela & B & 30 & Inverno & $03 / 09 / 70$ & Traina \\
\hline P3 & Moela & B & 30 & Inverno & $17 / 09 / 70$ & Traina \\
\hline $\mathrm{P} 4$ & Sul da Moela & B & 30 & Inverno & $25 / 09 / 70$ & Traina \\
\hline P5 & Moela & B & 30 & Inverno & $01 / 10 / 70$ & Traina \\
\hline P6 & Ilha de Alcatrazes & B & 30 & Primavera & $06 / 10 / 70$ & Traina \\
\hline p7 & Lage de Santos & B & 30 & Primavera & $22 / 10 / 70$ & Traina \\
\hline P8 & Sudoeste da Barra de Santos - 15 wilhas & B & 30 & Primavera & $29 / 10 / 70$ & Traina \\
\hline p9 & 15 milhas da Barra de Santos & B & 30 & Primavera & $05 / 11 / 70$ & Traina \\
\hline P10 & Lage de Santos & B & 30 & Primavera & $17 / 11 / 70$ & Traina \\
\hline P11 & Lage de Santos & B & 30 & Primavera & $19 / 11 / 70$ & Traina \\
\hline P11B & Est. $1283 \mathrm{~N} / 0 \mathrm{c}$. "Prof. W. Besnard" - Arrasto 30 & c & 07 & Primavera & $07 / 12 / 70$ & Otter-Trawl \\
\hline P12 & Ilha Grande & A & 30 & Verào & $08 / 12 / 71$ & Traina \\
\hline P13 & Ilha Grande & $\mathrm{A}$ & 30 & Veräo & $16 / 02 / 71$ & Traina \\
\hline P14 & Lage de Santos & B & 30 & Verão & $02 / 03 / 71$ & Traina \\
\hline P16 & Sueste da Barra de Santos - 25 milhas da costa & B & 30 & Verão & $09 / 03 / 71$ & Traina \\
\hline P17 & Moela. & B & 30 & Veräo & $22 / 03 / 71$ & Traina \\
\hline P19 & Canavieiras - Florianōpolis & $\mathbf{E}$ & 30 & Veräo & $24 / 03 / 71$ & Traina \\
\hline P 20 & Canavieiras - Florianopolis & E & 30 & Veräo & $24 / 03 / 71$ & Traina \\
\hline P21 & Florianopolis - Ponta das Canas & $\mathrm{E}$ & 30 & Veräo & $24 / 03 / 71$ & Traina \\
\hline P22 & Florianopolis - Ponta das Canas & $\mathrm{E}$ & 30 & Veräo & $24 / 03 / 71$ & Traina \\
\hline P23 & Ilha Grande & A & 30 & Outono & $04 / 05 / 71$ & Traina \\
\hline P24 & Monte de trigo & A & 30 & Outono & $05 / 05 / 71$ & Traina \\
\hline P25 & Lage de Santos & B & 30 & Outono & $15 / 06 / 71$ & Traina \\
\hline P26 & Lage de Santos & B & 30 & Outono & $15 / 06 / 71$ & Traina \\
\hline P27 & Lage de Santos & B & 30 & Outono & $16 / 06 / 71$ & Traina \\
\hline P28 & Entre $I$. Grande $e \mathrm{R}$. de Janeiro -20 milhas da costa & $\mathbf{A}$ & 30 & Outono & $19 / 06 / 71$ & Traina \\
\hline P29 & Sul da Joatinga & $\mathrm{A}$ & 30 & Outono & $20 / 06 / 71$ & Traina \\
\hline P30 & Sudeste da Barra de Santos & B & 30 & Outono & $27 / 06 / 71$ & Traina \\
\hline P31 & Cananéia - I. 0 . Base Sul & c & 30 & Outono & $15 / 05 / 71$ & Tarrafa \\
\hline P32 & Cananéia - I. 0. Base Sul & c & 30 & Outono & $17 / 05 / 71$ & Tarrafa \\
\hline P33 & Pinheiras - Florianopolis & $\mathrm{E}$ & 30 & Outono & $22 / 05 / 71$ & Tarrafa \\
\hline P34 & Pinheiras - Florianopolis & E & 30 & Outono & $22 / 05 / 71$ & Tarrafa \\
\hline P35 & Pinheiras - Florianopolis & $\mathbf{E}$ & 30 & Outono & $22 / 05 / 71$ & Tarrafa \\
\hline P36 & Pinheiras - Florianópolis & E & 30 & Outono & $22 / 05 / 71$ & Tarrafa \\
\hline P37 & Paranaguá (Dentro) & c & 30 & Outono & $01 / 06 / 71$ & Tarrafa \\
\hline P38 & Ilha do $\mathrm{Mel}$ & c & 30 & Outono & $02 / 06 / 71$ & Tarrafa \\
\hline P39 & Paranaguã & c & 30 & Outono & $02 / 06 / 71$ & Tarrafa \\
\hline P40 & Ilha do Mel & c & 30 & Outono & $02 / 06 / 71$ & Tarrafa \\
\hline P41 & Itajai - Ponta dos Cabeçudos & D & 30 & Outono & $18 / 05 / 71$ & Traina \\
\hline P42 & Itajaí - Ponta dos Cabeçudos & D & 30 & Outono & $18 / 05 / 71$ & Traina \\
\hline P43 & Itajaí - Ponta dos Cabeçudos & D & 30 & Outono & $18 / 05 / 71$ & Traina \\
\hline P44 & Itajaí - Ponta dos Cabeçudos & D & 30 & Outono & $18 / 05 / 71$ & Traina \\
\hline P45 & Paranagua - Pontal do Sul & c & 30 & Inverno & $26 / 08 / 71$ & Arrastä́o-de-praia \\
\hline P46 & Paranaguá - Pontal do Sul & c & 30 & Inverno & $26 / 08 / 71$ & Arrastäo-de-praia \\
\hline P47 & Paranaguá - Pontal do Sul & c & 30 & Inverno & $26 / 08 / 71$ & Arrastäo-de-praia \\
\hline $\mathrm{P} 48$ & Pontal do Sul. & c & 30 & Inverno & $26 / 08 / 71$ & Arrastão-de-praia \\
\hline P49 & Itajaî - Armasçāo Itapocoroi & D & 30 & Inverno & $18 / 08 / 71$ & Traina \\
\hline P50 & Itajaî - Armaçäo Itapocoroi & D & 30 & Inverno & $18 / 08 / 71$ & Traina \\
\hline P51 & Itajaî - Armação Itapocoroi & D & 30 & Inverno & $18 / 08 / 71$ & Traina \\
\hline P52 & Itajaí - Armação Itapocoroi & D & 30 & Inverno & $18 / 08 / 71$ & Traina \\
\hline P53 & Laguna - Garopava do Sul & E & 30 & Inverno & $18 / 08 / 71$ & Rede tipo portuguesa \\
\hline P54 & Laguna - Garopava do Sul & E & 30 & Inverno & $18 / 08 / 71$ & Rede tipo portuguesa \\
\hline P55 & Laguna - Garopava do Sul & $\mathrm{E}$ & 30 & Inverno & $18 / 08 / 71$ & Rede tipo portuguesa \\
\hline P56 & Laguna - Garopava do Su1 & $\mathrm{E}$ & 30 & Inverno & $18 / 08 / 71$ & Rede tipo portuguesa \\
\hline P57 & Picinguaba - Ubatuba & A & 30 & Inverno & $22 / 09 / 71$ & Traina \\
\hline P58 & Camburi - Ubatuba & $\ddot{A}$ & 30 & Inverno & $22 / 09 / 71$ & Traina \\
\hline P59 & Camburí - Ubatuba & A & 30 & Inverno & $23 / 09 / 71$ & Traina \\
\hline P60 & Caruçu - Ubatuba & $\ddot{A}$ & 30 & Inverno & $24 / 09 / 71$ & Traina \\
\hline P61 & Pinheiras - Forianópolis & $\mathrm{E}$ & 30 & Primavera & $20 / 11 / 71$ & Traina \\
\hline $\mathrm{P} 62$ & Pinheiras & $\mathrm{E}$ & 30 & Primavera & $20 / 11 / 71$ & Traina \\
\hline P63 & Pinheiras & $\mathrm{E}$ & 30 & Primavera & $20 / 11 / 71$ & Traina \\
\hline P64 & Pinheiras & E & 30 & Primavera & $20 / 11 / 71$ & Traina \\
\hline P65 & Ubatuba - Couves, 7 milhas da costa & A & 30 & Prímavera & $30 / 11 / 71$ & Traina \\
\hline P66 & Couves - 1 milha da praia & A & 30 & Primavera & $30 / 11 / 71$ & Traina \\
\hline P67 & Camburi, divisa com o Rio de Janeíro & A & 30 & Primavera & $01 / 12 / 71$ & Traina \\
\hline P68 & Ilha Anchieta & A & 30 & Primavera & $02 / 12 / 71$ & Trains \\
\hline P69 & Barra Velha - Itajai & D & 30 & Primavera & $25 / 11 / 71$ & Traina \\
\hline P70 & Barra Velha - Itajai & D & 30 & Primavera & $25 / 11 / 71$ & Traina \\
\hline P71 & Barra Velha - Itajai & D & 30 & Primavera & $25 / 11 / 71$ & Traina \\
\hline P72 & Barra Velha - Itajaí & D & 30 & Primavera & $25 / 11 / 71$ & Trains \\
\hline P73 & Cananéia - em frente à Base SuI & c & 30 & Primavera & $30 / 11 / 71$ & Tarrafa \\
\hline P74 & Cananéia - em frente ầ Base Sul & c & 30 & Primavera & $30 / 11 / 71$ & Tarrafa \\
\hline P75 & Cananéia - em frente ã Base Sul & c & 30 & Primavera & $30 / 11 / 71$ & Tarrafa \\
\hline P82 & Mar de Itajai & D & 30 & Veräo & $23 / 03 / 72$ & Traina \\
\hline P83 & Mar de Itajaí & D & 30 & Veräo & $23 / 03 / 72$ & Traina \\
\hline P84 & Mar de Itajaí & D & 30 & Veräo & $23 / 03 / 72$ & Traina \\
\hline P85 & Mar de Itajaí & D & 30 & Verão & $23 / 03 / 72$ & Traina \\
\hline
\end{tabular}


Em cada estação do ano, procurou-se abranger toda a extensão de cada sub-área com a coleta de amostras de locais bem distintos. Foram amostrados no total 78 cardumes englobando 2.317 exemplares.

De cada amostra foram anotadas informações sobre data e local de coleta e método de captura. Os dados sobre os quais está baseado o presente estudo estão arquivados junto ao Departamento de Oceanografia Biológica do Instituto Oceanogräfico da Universidade de São Paulo.

Cada exemplar foi medido a fresco, tomando-se a medida do comprimento total, da ponta do focinho até a extremidade do lobo mais longo da nadadeira caudal, ligeiramente distendida; a medida foi feita em projeção horizontal sobre um ictiômetro com o exemplar deitado sobre seu flanco direito, sendo as medidas tomadas em milímetros, com aproximação para a unidade inferior. 0 comprimento total ( $L_{t}$ ) variou de 70 a 255 milímetros.

A pesagem de cada exemplar foi realizada em balança tipo Welsh com precisão de atē $0,1 \mathrm{~g}$; os peixes foram pesados intactos, com gônadas, trato digestivo e demais órgãos, limpos de qualquer sujeira aderente e úmidos apenas pelo muco natural da superfície. 0 peso total $\left(W_{t}\right)$ variou de 3,50 a 130,00 gramas.

Em cada exemplar foi realizada uma incisão abdominal e determinados, macroscopicamente, o sexo e estádio de maturidade das gônadas, baseando-se numa escala de quatro estádios (Vazzoler, 1971), como segue: I. Estádio A: imaturo; II. Estādio B: em maturação; III. Estádio C: maduro; IV. Estádio D: esvaziado.

Dos mesmos exemplares foram anotados dados sobre proporções corporais e caracteres merísticos, cuja análise está sendo realizada.

\section{MÉTODOS DE ANÁLISE DOS DADOS}

Na primeira fase de análise, procurou-se estabelecer qual(is) a(s) expressão(ões) matemática(s) que melhor se ajustava(m) aos dados sobre peso total e comprimento total, tanto para amostras de cardumes individuais como para os dados grupados por estação do ano, em cada sub-área. 
Para tanto aplicou-se teste de especificação (Leme, 1958) aos dados sobre peso total e comprimento total, relativos a cada amostra de cardume e aos dados grupados de cada sub-área, tendo-se selecionado para o primeiro caso a expressão de forma $y=a+b x$ e, para o segundo, $y=a_{x} b$ (Figs 2-3). Tais expressões foram ajustadas aos dados pelo método dos mínimos quadrados.

Testou-se a homogeneidade da relação entre sexos (teste de "t", nível de $5 \%$ e, tendo sido constatado não haver dimorfismo sexual, os dados foram grupados tanto para amostras de cardumes isolados, como por estação do ano, dentro de cada sub-ārea (Figs 2 e 4; Tab. II).

Como indivíduos menores que $137 \mathrm{~mm}$ não foram amostrados em todas as subáreas, durante as quatro estações, procurou-se um critério com base biológica para selecionar o intervalo de comprimento total que seria considerado no estudo. Calculou-se então o comprimento total médio em que $50 \%$ dos indivíduos da espécie inicia o processo de primeira maturação sexual. Para a anālise, os exemplares foram grupados em imaturos (estádio A) e adultos (es-
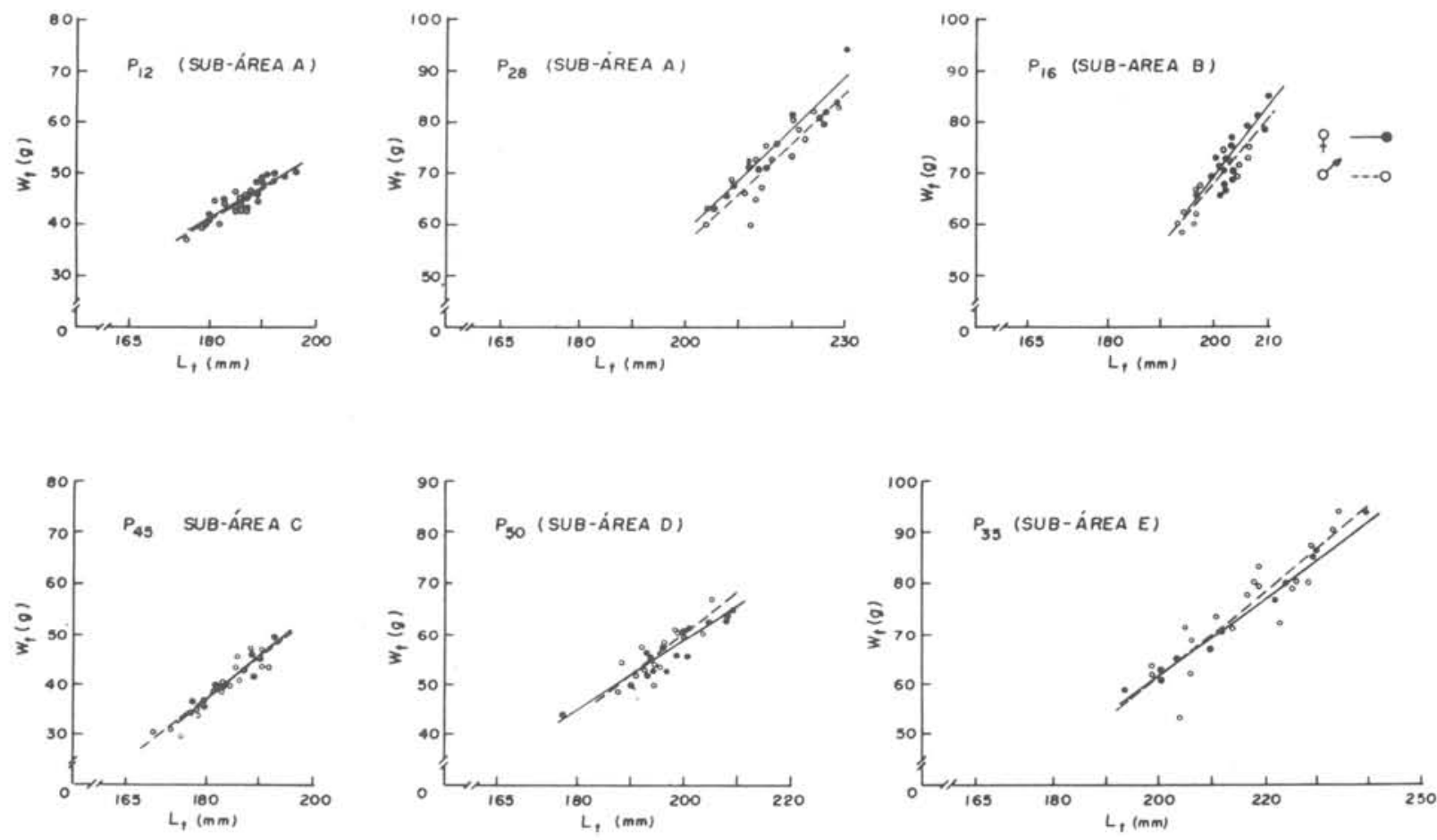

Fig. 2 - Exemplos grä́ficos de regressões entre peso total (g) e comprimento total (mm) para dados relativos a amostras de cardumes individuais, para sexos separados. 


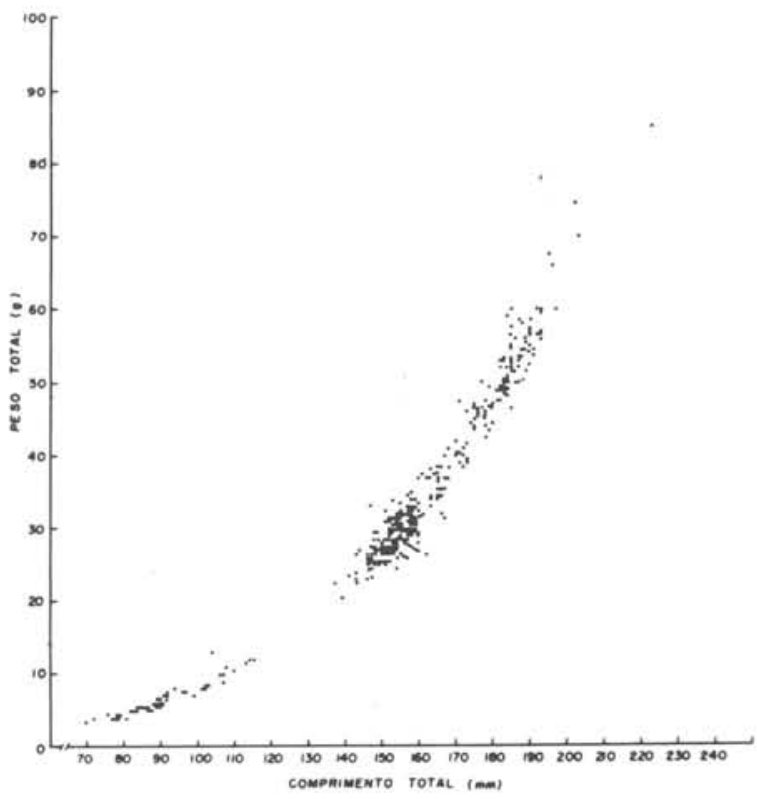

Fig. 3 - Gräfico exemplificando a tendência da variação do peso total (g) em relação à do comprimento total (mm); dados relativos a todos os exemplares amostrados na sub-ärea $C$.

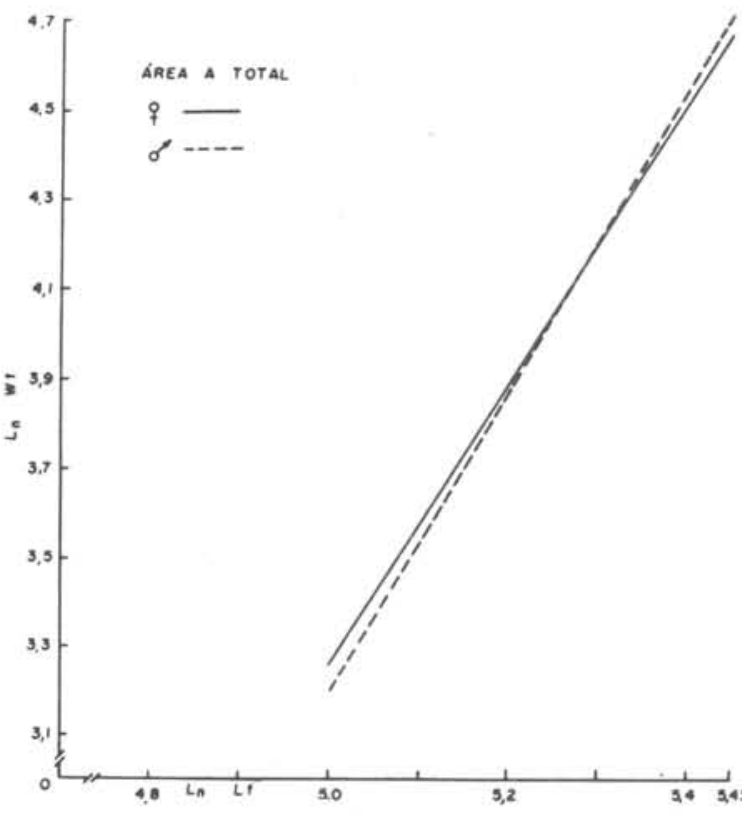

Fig. 4 - Exemplo gräfico de regressões obtidas entre logaritmo do peso total $\left(1 w_{t}\right)$ e logarítmo do comprimento total $\left(1_{n} L_{t}\right)$, para sexos separados; dados relativos aos exemplares coletados na sub-ärea $A$.

TABELA II-A - Dados das regressões entre logarítmos do peso total $\left(I_{n} W_{t}\right)$ e logarítmo do comprimento total $\left(I_{n} L_{t}\right)$ dos Individuos coletados na sub-ärea $A$, durante todo o período estudado, por sexo

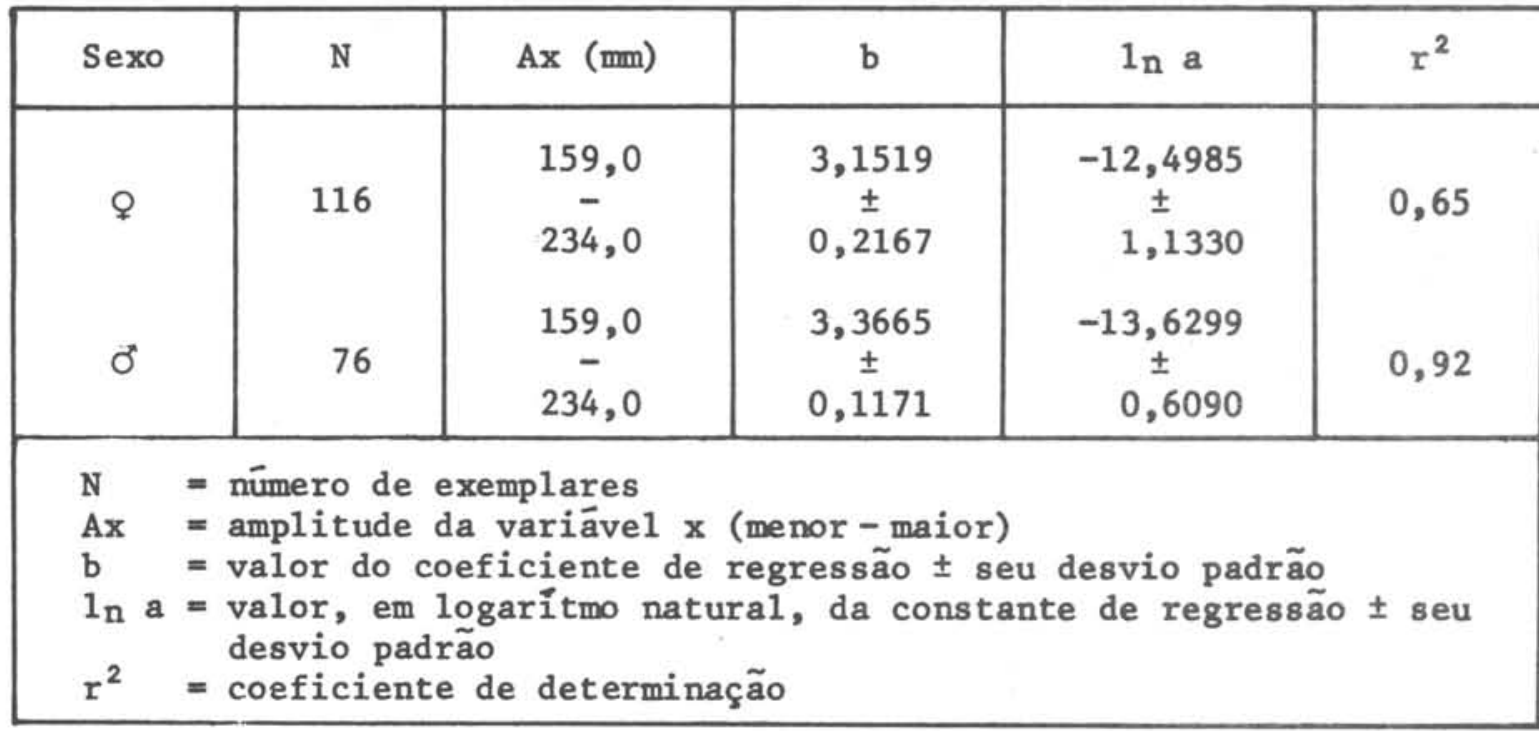


TABELA II-B - Resultado do teste de " $t$ " aplicado às regressões entre sexos

\begin{tabular}{|c|c|c|c|}
\hline Teste entre & $\mathrm{n}$ & $\mathrm{t}(\mathrm{b})$ & $\mathrm{t}(\mathrm{a})$ \\
\hline$\uparrow / \sigma$ & 192 & 0,65 & 0,94 \\
\hline
\end{tabular}

tádios B, C e D) e calculou-se a freqüência relativa de ocorrência de cada grupo, por classe de comprimento total, por sub-área, para todo o período estudado. As freqüências de adultos por classe de comprimento total foram lançadas em gräfico e a mediana determinada graficamente. Determinou-se também o comprimento total em que $100 \%$ dos indivíduos da espécie atinge a maturidade sexual (Vazzoler, 1962, 1971) (Tab. III; Fig. 5).

A inspeção dos gräficos mostrou que os resultados nas cinco sub-áreas eram praticamente os mesmos, sendo $165 \mathrm{~mm}$ o comprimento total médio do início da primeira maturação sexual para a espécie.

Com base nos resultados obtidos, prosseguimos o estudo, considerando apenas os indivíduos adultos, ou seja, com comprimento total acima de $165 \mathrm{~mm}$.

Aos dados grupados segundo o critério anterior, foi ajustada a expressão $W_{t}=a L_{t}{ }^{b}$, onde $W_{t}=$ peso total $(\mathrm{g}), L_{t}=$ comprimento total (mm), $a=$ constante de regressão e $b=$ coeficiente de regressão (Tab. IV).

TABELA III - Comprimento total mëdio do início da primeira maturação sexual $\left(\bar{L}_{m}\right)$ e comprimento total médio em que $100 \%$ dos indivíduos atingem a maturidade sexual $\left(\bar{L}_{100 \%}\right)$ em cada sub-ärea considerada

\begin{tabular}{|c|c|c|}
\hline Sub-ärea & $\overline{\mathrm{L}}_{\mathrm{m}}(\mathrm{mm})$ & $\overline{\mathrm{L}}_{100 \%}(\mathrm{~mm})$ \\
\hline A & 164 & 200 \\
B & 164 & 230 \\
C & 166 & 190 \\
D & 160 & 220 \\
E & 164 & 225 \\
\hline
\end{tabular}


TABELA IV - Dados das regressões entre logarítmo do peso total $\left(\ln _{\mathrm{n}}\right)$ e logaritmo do comprimento total $\left(I_{n} L_{t}\right)$ de $S$. brasiliensis, para sexos grupados, por estação do ano, para cada sub-ärea

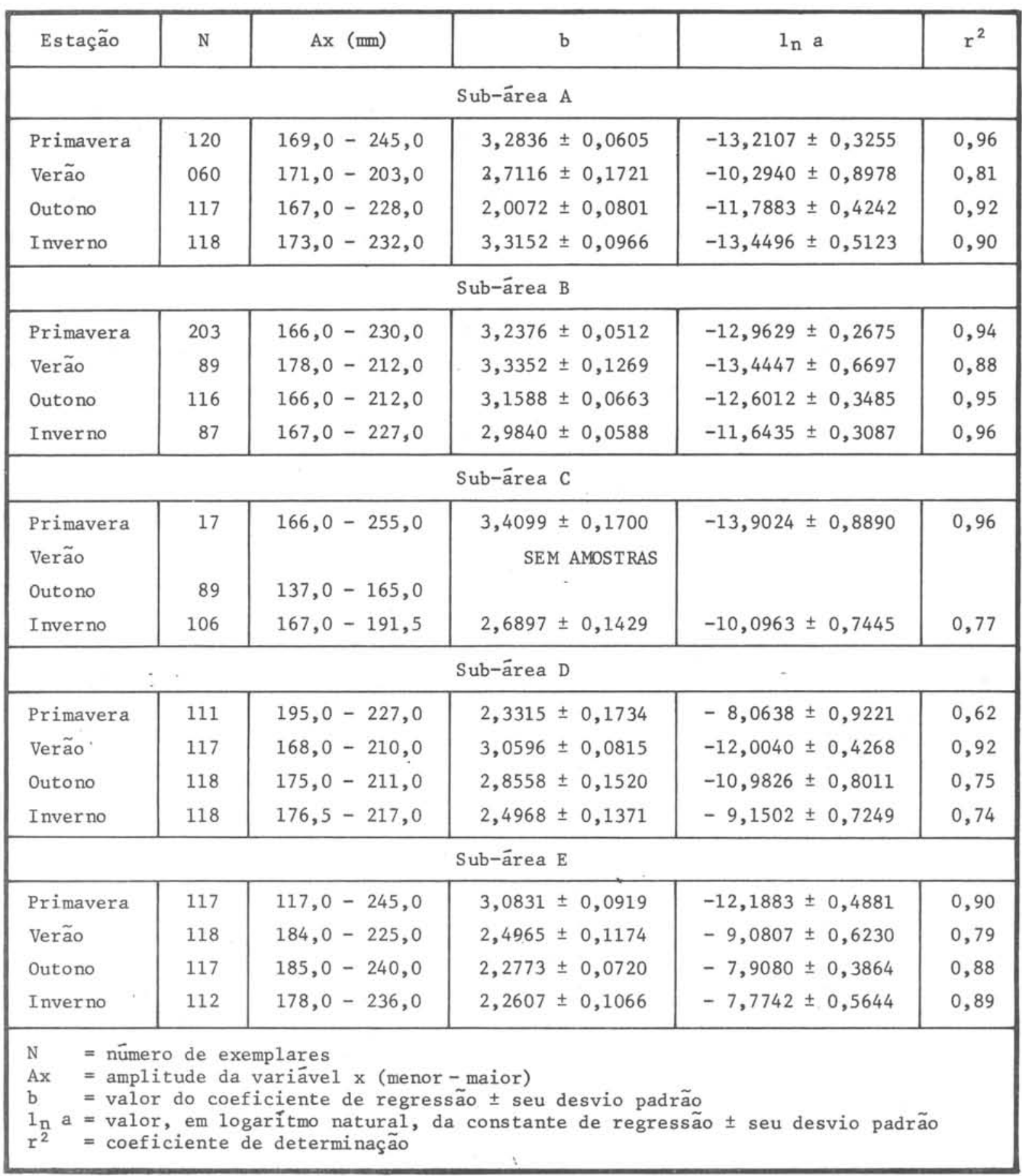



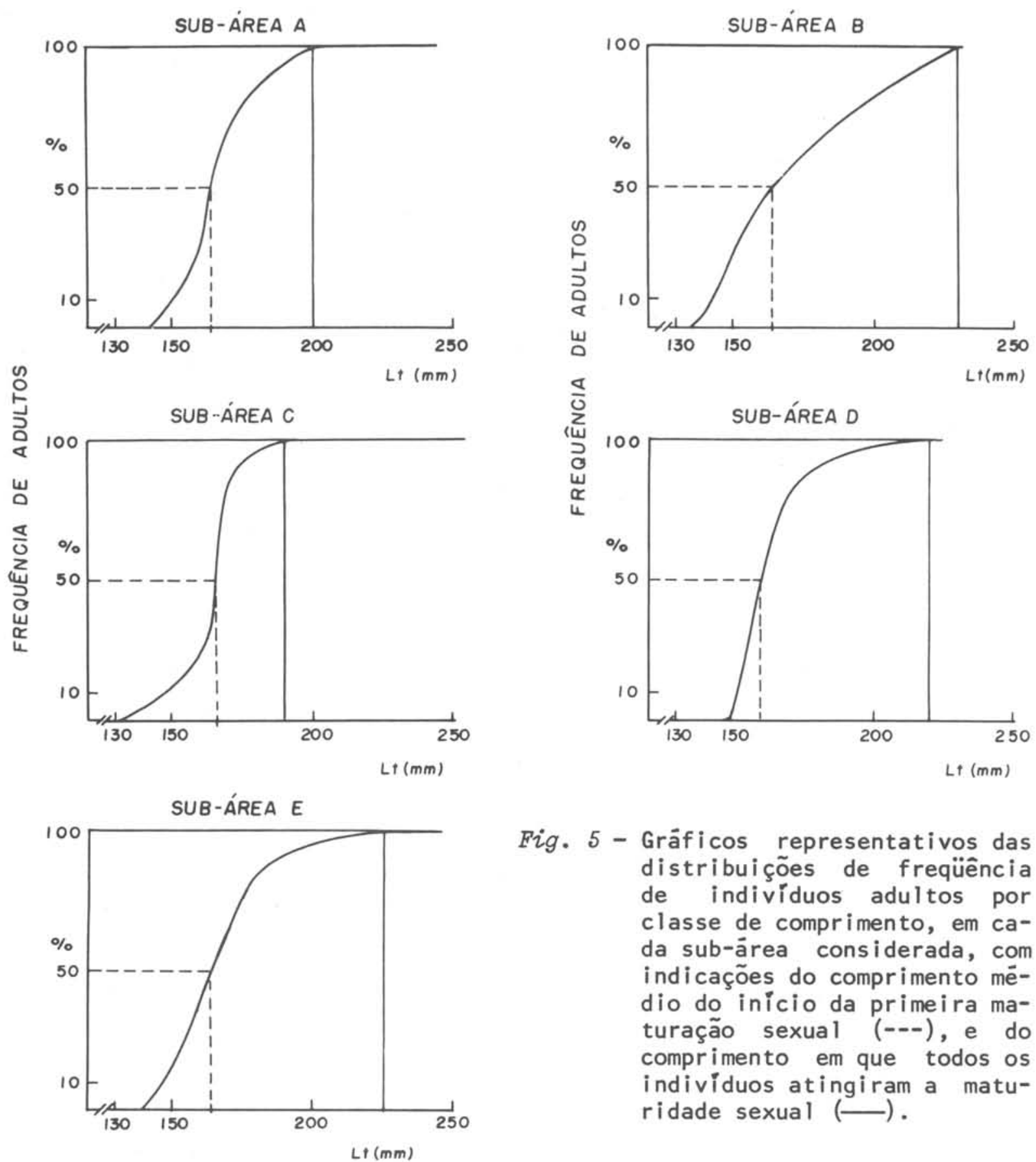

Fig. 5 - Gräficos representativos das distribuições de freqüência de indivíduos adultos por classe de comprimento, em cada sub-ärea considerada, com indicações do comprimento médio do inicio da primeira maturação sexual (---), e do comprimento em que todos os individuos atingiram a maturidade sexual $(\longrightarrow)$.

Foi feita anālise comparativa da relação peso total/comprimento total, entre cardumes, por sub-ärea entre estações do ano e por estação do ano entre sub-äreas.

Os resultados foram testados quanto a sua homogeneidade, como segue:

a) cardumes: o teste constituiu na inspeção visual das retas representativas 
de relação $W_{t} / L_{t}$ para os cardumes amostrados dentro de uma mesma sub-ärea e estação do ano. Observou-se que cada cardume é parte da curva geral representativa da relação $W_{t} / L_{t}$; em vista disso, os mesmos foram grupados por estação do ano, dentro de cada sub-ärea;

b) por sub-área, entre estações do ano: aos dados de cardumes pertencentes a uma mesma sub-ārea e estação do ano, foi ajustada equação do tipo $y=a x^{b}$ pelo método dos mínimos quadrados, após transformação logarítmica. Os resultados foram testados quanto a sua homogeneidade através de análise de variância e teste de comparação mültipla dos coeficientes e constantes de regressão, pelo método de Kramer (1956) (Figs 6-10);

c) por estação do ano, entre sub-áreas: a metodologia aplicada foi seme1hante a descrita no item anterior (Figs 11-14).

Para interpretar uma das possíveis causas das variações observadas foram determinadas as épocas e locais de desova da espécie.

Assim, os dados relativos à ocorrência de fêmeas nos quatro estádios de maturidade foram distribuídos por estação do ano, para cada uma das cinco sub-āreas consideradas, e calculadas suas freqüências relativas dentro de cada sub-área, para cada estação e para o perỉodo global (Tab. V).

Os resultados foram lançados em gräfico para se obter indicações quanto às épocas de desova (Fig. 15) e possíveis movimentos dos indivíduos de uma sub-ārea para outra (Fig. 16).

Para se ter indicações dos locais de desova foi calculada a frequência relativa das fêmeas com gônadas em estádio $C$ e $D$, ao longo de toda a região durante as estações do ano (Tab. VI). Os resultados foram lançados em mapa, obtendo-se assim uma visão da distribuição espacial e temporal desses indivỉduos (Fig. 17).

Para se ter uma indicação dos padrões de variação dos pesos totais médios durante as estações do ano, dentro de cada sub-ārea, e entre as subáreas durante as estações do ano, para indivỉduos que "estão iniciando pela primeira vez o processo de maturação sexual", para "adultos pequenos" e para "adultos grandes" (Vazzoler \& Vazzoler, 1965), estimou-se tais pesos para as classes de comprimento de 170, 200 e $240 \mathrm{~mm}$ que representam respectivamente, tais grupos de indivíduos (Figs 6C-14C). 
TABELA V - Distribuição de freqüênclas dos estädios de maturidade de fêmeas por sub-ärea durante as estações do ano e para o perlodo total

\begin{tabular}{|c|c|c|c|c|c|c|c|c|c|c|c|}
\hline \multirow{2}{*}{ Sub-ārea } & \multirow{2}{*}{$\begin{array}{l}\text { Estádio de } \\
\text { maturidade }\end{array}$} & \multicolumn{2}{|c|}{ Primavera } & \multicolumn{2}{|c|}{ Verão } & \multicolumn{2}{|c|}{ Outono } & \multicolumn{2}{|c|}{ Inverno } & \multicolumn{2}{|c|}{ Total } \\
\hline & & No & $\%$ & No & $\%$ & NQ & $z$ & No & $\pi$ & NQ & $\pi$ \\
\hline \multirow{4}{*}{ A } & A & 0 & 0,0 & 2 & 1,0 & 12 & 5,9 & 9 & 4,4 & 23 & 11,4 \\
\hline & B & 10 & 5,0 & 5 & 2,5 & 34 & 16,8 & 55 & 27,2 & 104 & 51,5 \\
\hline & c & 46 & 22,8 & 13 & 6,4 & 9 & 4,4 & 0 & 0,0 & 68 & 33,7 \\
\hline & D & 0 & 0,0 & 7 & 3,5 & 0 & 0,0 & 0 & 0,0 & 7 & 3,5 \\
\hline \multirow{4}{*}{ B } & A & 62 & 22,2 & 5 & 1,8 & 2 & 0,7 & 18 & 6,5 & 87 & 31,2 \\
\hline & B & 37 & 13,3 & 24 & 8,6 & 52 & 18,7 & 34 & 12,2 & 147 & 52,8 \\
\hline & c & 18 & 6,5 & 16 & 5,7 & 0 & 0,0 & 1 & 0,4 & 35 & 12,6 \\
\hline & D & 0 & 0,0 & 9 & 3,2 & 0 & 0,0 & 0 & 0,0 & 9 & 3,2 \\
\hline \multirow{4}{*}{ C } & A & 54 & 31,4 & \multirow{4}{*}{\multicolumn{2}{|c|}{$\begin{array}{c}\text { SEM } \\
\text { AMOSTRA }\end{array}$}} & 62 & 36,0 & 0 & 0,0 & 116 & 67,4 \\
\hline & B & 0 & 0,0 & & & 0 & 0,0 & 56 & 32,5 & 56 & 32,5 \\
\hline & C & 0 & 0,0 & & & 0 & 0,0 & 0 & 0,0 & 0 & 0,0 \\
\hline & D & 0 & 0,0 & & & 0 & 0,0 & 0 & 0,0 & 0 & 0,0 \\
\hline \multirow{4}{*}{ D } & A & 0 & 0,0 & 3 & 1,5 & 7 & 3,5 & 0 & 0,0 & 10 & 5,1 \\
\hline & B & 19 & 9,5 & 41 & 20,8 & 34 & 17,2 & 53 & 26,9 & 147 & 74,5 \\
\hline & C & 39 & 19,8 & 0 & 0,0 & 0 & 0,0 & 0 & 0,0 & 39 & 19,8 \\
\hline & D & 1 & 0,5 & 0 & 0,0 & 0 & 0,0 & 0 & 0,0 & 1 & 0,5 \\
\hline \multirow{4}{*}{ E } & A & 4 & 1,8 & 6 & 2,7 & 1 & 0,4 & 0 & 0,0 & 11 & 4,9 \\
\hline & B & 52 & 23,2 & 30 & 13,4 & 57 & 25,4 & 59 & 26,3 & 198 & 88,3 \\
\hline & C & 4 & 1,8 & 5 & 2,2 & 0 & 0,0 & 0 & 0,0 & 9 & 4,0 \\
\hline & D & 0 & 0,0 & 5 & 2,2 & 1 & 0,4 & 0 & 0,0 & 6 & 2,7 \\
\hline
\end{tabular}

0 processamento dos dados foi efetuado utilizando-se computador-de-mesa 0livetti Programa 101, computador B-3500 do Centro de Computação Eletrônica do Instituto de Matemática e Estatística da Universidade de São Paulo e computador IBM/360 do Instituto de Física da Universidade de São Paulo.

Estudos em andamento sobre a estrutura da espécie, mostraram a existência conjunta de indivíduos com elevado (>150) e com baixo (< 150) número de rastros no ramo inferior do primeiro arco branquial, na área estudada. Como tal carater é utilizado para detectar ocorrência de populações, raças ou espécies distintas, achou-se por bem testar a relação em estudo para os dois 
grupos. Foram calculadas e testadas quanto sua homogeneidade as regressões $W_{t} / L_{t}: 1$ ) entre sexos; 2) por cardume e 3 ) por estação do ano, para os dois grupos acima citados; não tendo sido encontradas variações significativas foram os mesmos grupados para análise.

TABELA VI - Freqüência relativa de ocorrência de fêmeas nos estädios C (maduro) e D (esvaziado), durante as estações do ano, dentro das clnco sub-äreas consideradas

\begin{tabular}{|c|c|c|c|c|c|c|c|c|}
\hline \multirow{2}{*}{ Sub-ārea } & \multicolumn{2}{|c|}{ Primavera } & \multicolumn{2}{|c|}{ Verão } & \multicolumn{2}{|c|}{ Outono } & \multicolumn{2}{|c|}{ Inverno } \\
\hline & No & $\%$ & No & $\%$ & No & $\%$ & No & $\%$ \\
\hline \multicolumn{9}{|c|}{ Estādio C } \\
\hline A & 46 & 30,4 & 13 & 8,6 & 9 & 6,0 & 0 & 0,0 \\
\hline B & 18 & 12,0 & 16 & 10,6 & 0 & 0,0 & 1 & 0,7 \\
\hline C & 0 & 0,0 & - & - & 0 & 0,0 & 0 & 0,0 \\
\hline D & 39 & 25,8 & 0 & 0,0 & 0 & 0,0 & 0 & 0,0 \\
\hline E & 4 & 2,6 & 5 & 3,3 & 0 & 0,0 & 0 & 0,0 \\
\hline \multicolumn{9}{|c|}{ Estādio D } \\
\hline A & 0 & 0,0 & 7 & 30,4 & 0 & 0,0 & 0 & 0,0 \\
\hline B & 0 & 0,0 & 9 & 39,2 & 0 & 0,0 & 0 & 0,0 \\
\hline C & 0 & 0,0 & - & - & 0 & 0,0 & 0 & 0,0 \\
\hline D & 1 & 4,4 & 0 & 0,0 & 0 & 0,0 & 0 & 0,0 \\
\hline $\mathrm{E}$ & 0 & 0,0 & 5 & 21,8 & 1 & 4,4 & 0 & 0,0 \\
\hline
\end{tabular}

\section{RESULTADOS}

A análise dos resultados obtidos para as relações entre peso total (g) e comprimento total (mm) de amostras de cardumes individuais, mostra que para cada cardume a relação é expressa por uma equação do tipo y = a + bx; o fato de ser esta a equação que melhor se ajusta aos dados, provavelmente, se deve 
à pequena amplitude de classes de comprimento que ocorre em cada cardume. 0 constatado acima está exemplificado na Figura 2 onde são apresentados exemplos de regressões para cardumes das várias sub-āreas, em diferentes estações do ano. Assim, na amostra P12 (sub-área A) o comprimento dos indivíduos variou entre 175-190 mm; na P45 (sub-área C) hā maior amplitude de classes de comprimento, mas ainda ao redor de 170-190 mm. Jā na P28 (sub-ārea A) e P16 (sub-área B) os indivíduos pertencem a classes de comprimento entre 200 e $230 \mathrm{~mm}$ na primeira e 190 a $210 \mathrm{~mm}$ na segunda. Nas amostras P50(sub-ärea D) e P35 (sub-ärea E), os comprimentos que ocorreram foram entre 180-210 mm e 190-240 mm, respectivamente.

A anālise dos dados relativos a todos os indivíduos de uma sub-ärea mostra que, para Sardinella brasiliensis, a relação entre peso total (g) e comprimento total (mm) é do tipo $y=a x^{b}$ (Fig. 3), sendo que a reta representativa da relação para cada cardume è parte desta curva global.

Do estudo da relação entre peso total/comprimento total, entre sexos, resultou não haver dimorfismo sexual para a espécie, na área considerada (Tab. II; Figs 2 e 4 ).

Para Sardinella brasiliensis o valor do comprimento médio do início da primeira maturação sexual não apresentou variações considerāveis nas cinco sub-äreas, sendo que o valor médio encontrado foi de 164,8 mm (Tab. III). Considerou-se o valor de $165 \mathrm{~mm}$ como representativo do comprimento médio em que $50 \%$ dos indivíduos da espécie iniciam o processo de maturação sexual. Para o comprimento estimado em que $100 \%$ dos indivíduos atinge a maturidąde sexual encontrou-se valores distintos para cada uma das sub-äreas estudadas. Este valor na sub-ärea A foi de $200 \mathrm{~mm}$; na sub-ārea B de $230 \mathrm{~mm}$; na sub-área $C$ de $190 \mathrm{~mm}$; na sub-ärea D de $220 \mathrm{~mm}$ e na sub-ärea E de $225 \mathrm{~mm}$. A inclinação das curvas representativas das distribuições de freqüência de indivíduos adultos (Fig. 5) mostrou-se diferente em cada uma das cinco sub-äreas, a partir do ponto de $50 \%$ (primeira maturação sexual). Poder-se-ia conjecturar que após a primeira maturação, os indivíduos de cada ārea têm seu processo de maturação completado ou em tempos diferentes ou, então, os indivíduos passam a apresentar taxas de crescimento diferentes.

Deve-se salientar que o valor registrado para a sub-ärea c é de validade relativa, uma vez que nesta sub-ārea, durante todo o período estudado (20 
meses) só foram registrados exemplares jovens (estádio A) e adultos no estádio B (Tab. V), não ocorrendo indivỉduos com gônadas maduras ou esvaziadas (estádio C e D).

0 teste de Kramer aplicado às regressões representativas da relação entre peso total $(\mathrm{g})$ e comprimento total $(\mathrm{mm})$, entre estações do ano, para cada uma das cinco sub-äreas, resultou:

I) para o coeficiente de regressão (b) que expressa a taxa de incremento em peso: na sub-ärea A, homogeneidade entre primavera e verão, e outono e inverno (Fig. 6B); na sub-ārea $B$, homogeneidade entre primavera, verão e outono, e outono e inverno (Fig. 7B); na sub-ärea C, heterogeneidade entre primavera e inverno (Fig. 8B); na sub-ärea $D$, homogeneidade entre verão e outono, outono e inverno, inverno e primavera (Fig. 9B), e na sub-ārea $\mathrm{E}$, homogeneidade entre verão, outono e inverno e primavera isolada (Fig. 10B).

II) para a constante de regressão (a) das retas representativas da relação, nas sub-āreas, heterogeneidade entre todas as estações do ano (Figs 6B10B).

Os resultados obtidos não nos permitiram grupar os dados relativos às distintas estações do ano em nenhuma das cinco sub-āreas.

0 teste de homogeneidade das regressões entre peso total ( $\mathrm{g}$ ) e comprimento total (mm), por estação do ano, entre as sub-āreas estudadas, resultou:

I) para o coeficiente de regressão (b): na primavera, äreas A, B, C, e B homogêneas, com ārea D isolada (Fig. 11B); no verão, āreas A e E, A e D e D e B homogêneas (Fig. 12B); no outono, áreas A, B e D homogêneas, e área E isolada (Fig. 13B); no inverno, āreas B e C, C e D e E homogêneas e área A isolada (Fig. 14B).

II) para a constante de regressão (a) durante cada estação do ano, entre as sub-äreas, o padrão obtido pelo teste de Kramer foi: na primavera, subāreas A e B, C e E homogêneas e D isolada (Fig. 11B); no verão, subāreas A, B, D e E isoladas (Fig. 12B); no outono, sub-äreas A e D homogêneas, B e E isoladas (Fig. 13B); no inverno, sub-äreas B e C homogêneas, A, D e E isoladas (Fig. 14B). Não foram coletados indivíduos maiores que $165 \mathrm{~mm}$, na sub-área $C$, no verão e outono. 


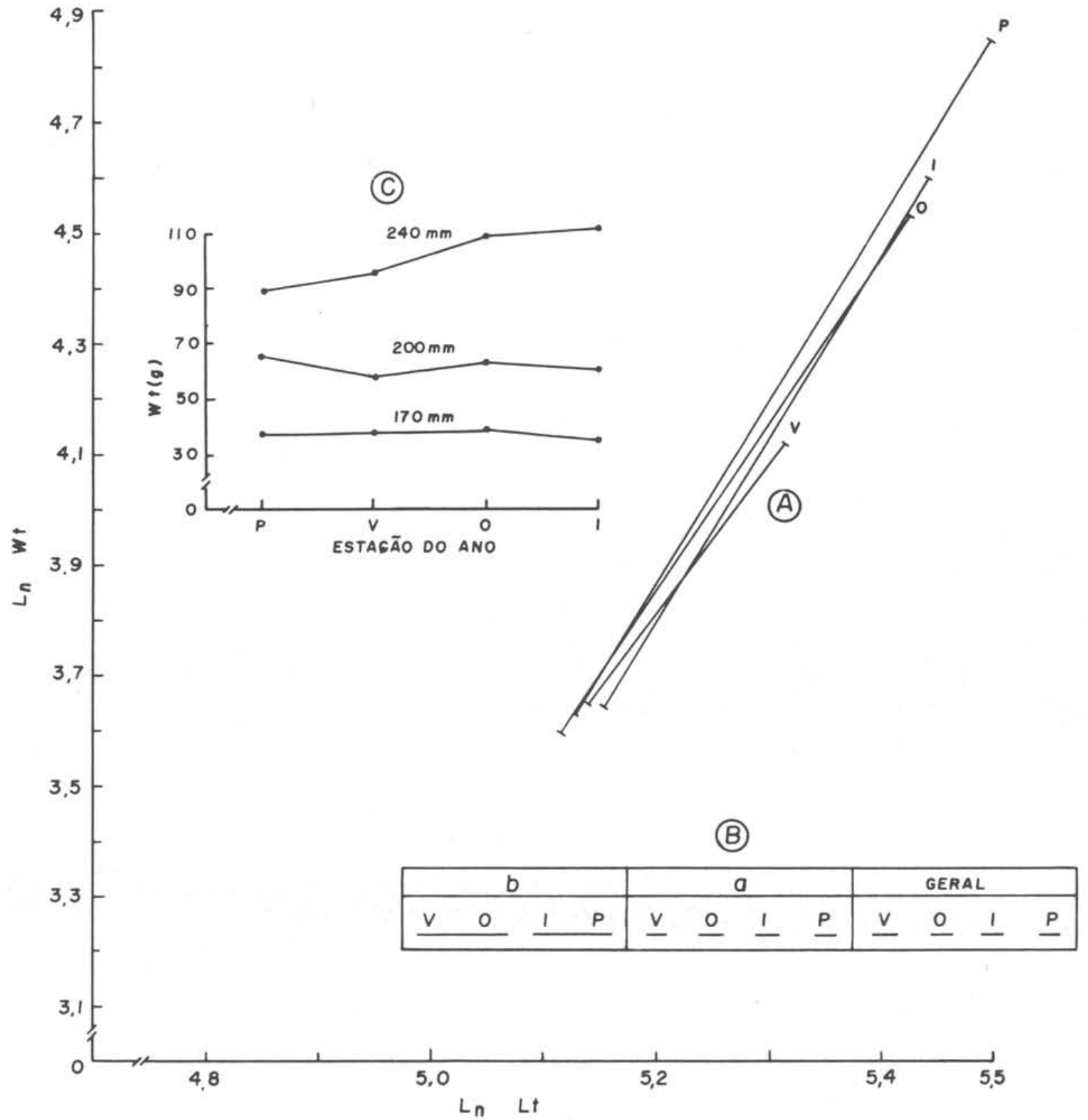

Fig. 6-A - Representação gräfica das retas de regressão entre logarítmo do peso total $\left(1_{n} W_{t}\right)$ e logarítmo do comprimento total $\left(1_{n} L_{t}\right)$, para cada estação do ano dentro da sub-ärea $A$.

$B$ - Representação dos resultados do teste de Kramer aplicado aos coeficientes (b) e constantes (a) das regressões acima citadas, e do padrão geral obtido para a sub-ärea $A$.

C - Variação dos pesos totais mëdios estimados para as classes de comprimento de $170 \mathrm{~mm}, 200 \mathrm{~mm}$ e $240 \mathrm{~mm}$, durante as estações do ano, para a sub-ärea $A$. 


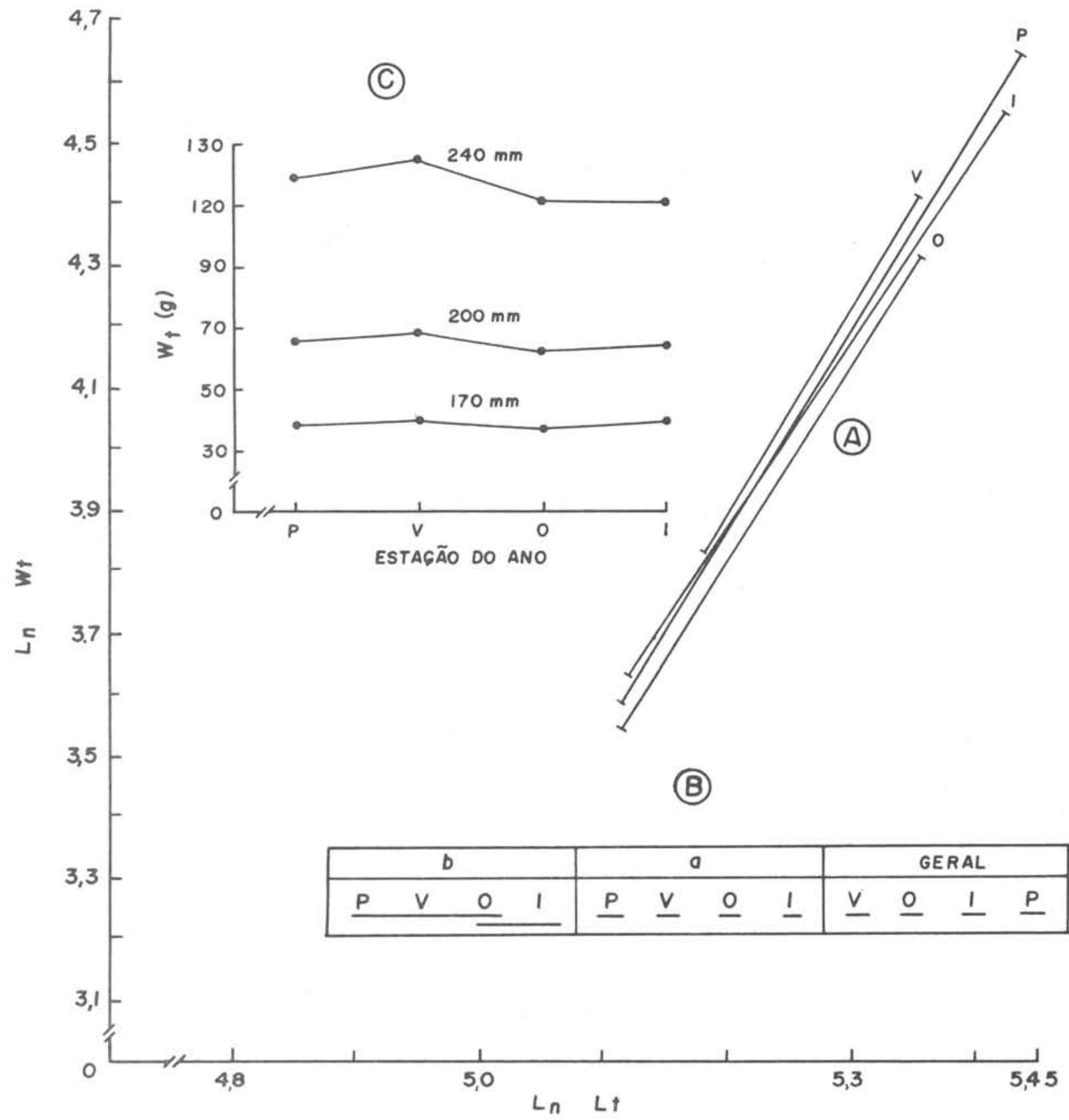

Fig. 7-A - Representação gräfica das retas de regressão entre logarítmo do peso total $\left(1_{n} W_{t}\right)$ e logarítmo do comprimento total $\left(1_{n} L_{t}\right)$, para cada estação do ano dentro da sub-ärea B.

$B$ - Representação dos resultados do teste de Kramer aplicado aos coeficientes (b) e constantes (a) das regressões acima cl tadas, e do padrão geral obtido para a sub-área $B$.

$C$ - Variação dos pesos totais mëdios estimados para as classes de comprimento de $170 \mathrm{~mm}, 200 \mathrm{~mm}$ e $240 \mathrm{~mm}$, durante as estações do ano, para a sub-ärea B. 


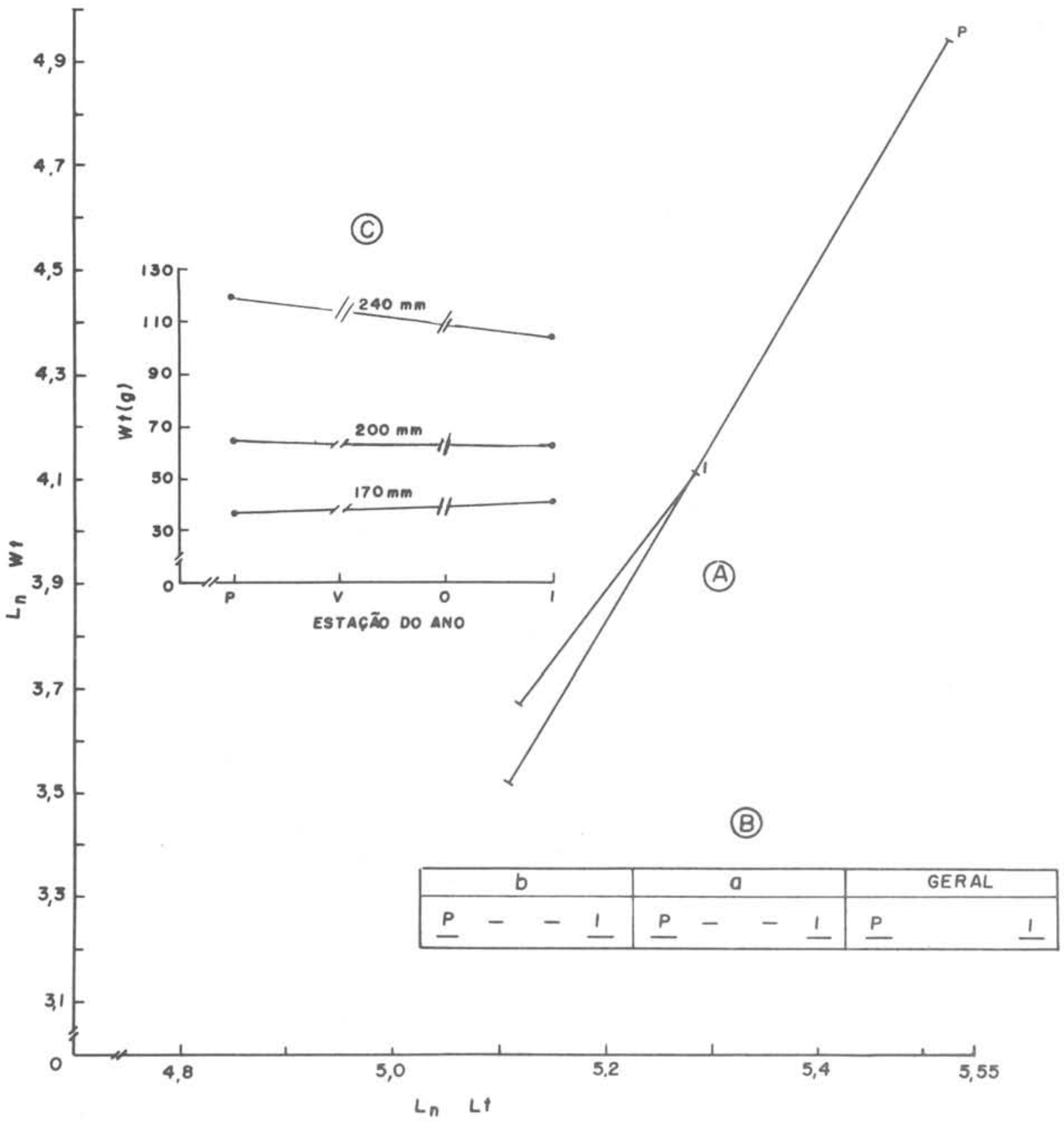

Fig. 8-A - Representação gräfica das retas de regressão entre logarítmo do peso total $\left(1_{n} W_{t}\right)$ e logaritmo do comprimento total $\left(1_{n} L_{t}\right)$, para cada estação do ano dentro da sub-ärea $C$.

$B$ - Representação dos resultados do teste de Kramer aplicado aos coeficientes (b) e constantes (a) das regressões acima citadas, e do padrão geral obtido para a sub-área C.

C - Variação dos pesos totais mëdios estimados para as classes de comprimento de $170 \mathrm{~mm}, 200 \mathrm{~mm}$ e $240 \mathrm{~mm}$, durante as estações do ano, para a sub-ärea C. 


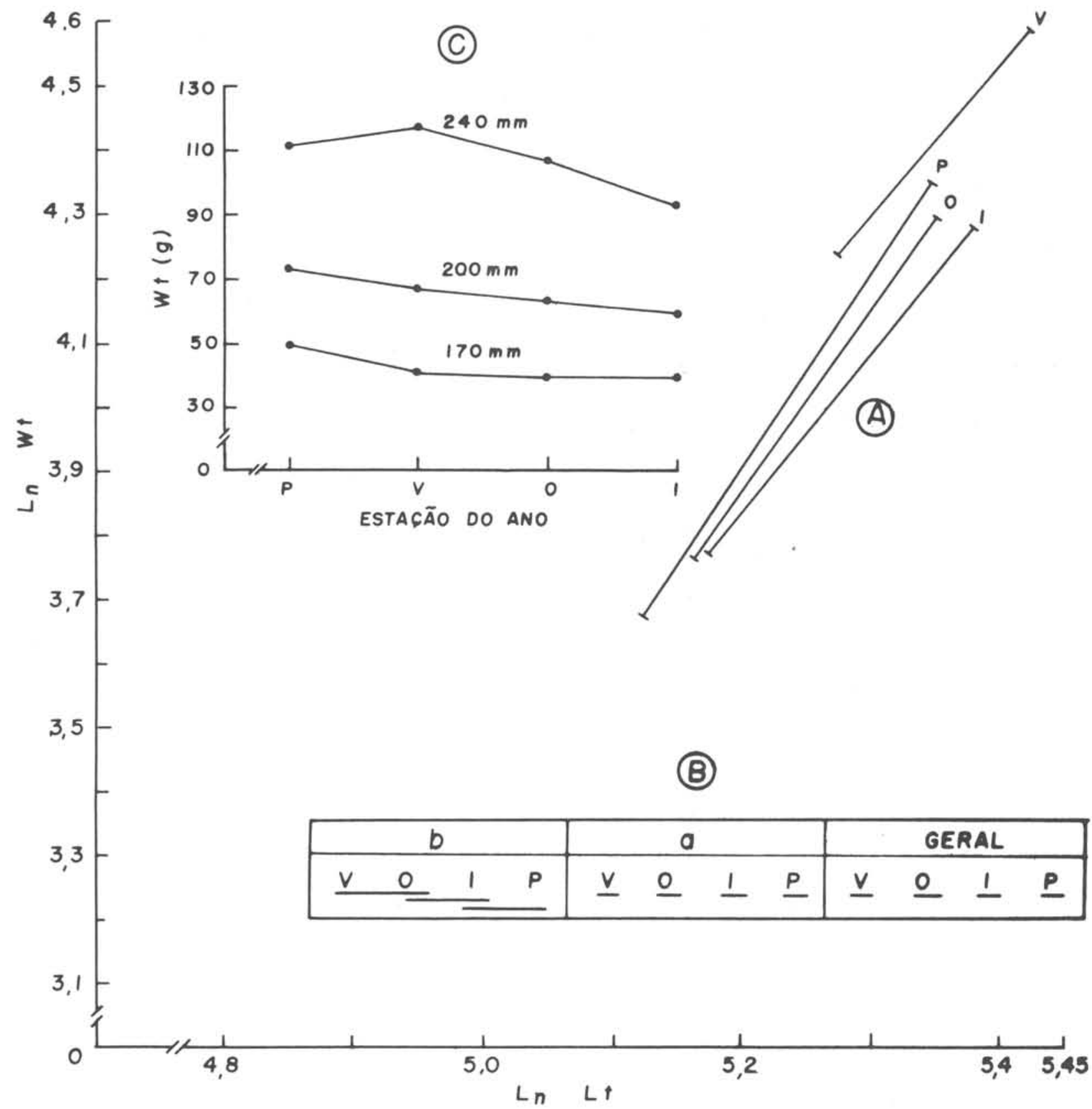

Fig. 9-A - Representação gräfica das retas de regressão entre logarítmo do peso total $\left(l_{n} W_{t}\right)$ e logarítmo do comprimento total $\left(I_{n} L_{t}\right)$, para cada estação do ano dentro da sub-ärea $D$.

$B$ - Representação dos resultados do teste de Kramer aplicado aos coeficientes (b) e constantes (a) das regressões acima citadas, e do padrão geral obtido para a sub-ärea $D$.

C - Variação dos pesos totais mëdios estimados para as classes de comprimento de $170 \mathrm{~mm}, 200 \mathrm{~mm}$ e $240 \mathrm{~mm}$, durante as estações do ano, para a sub-ärea D. 


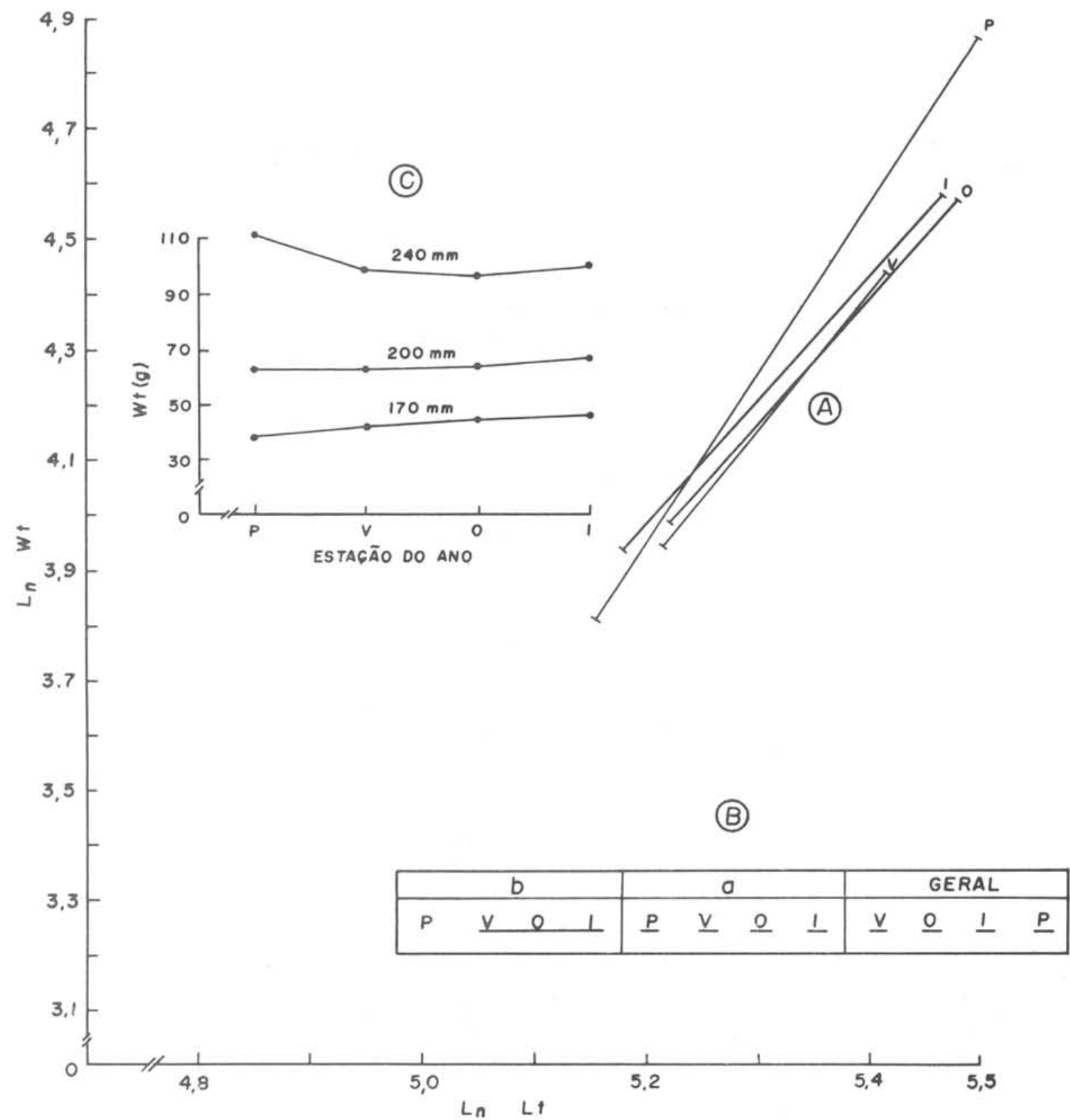

Fig. 10-A - Representação gräfica das retas de regressão entre logarítmo do peso total $\left(I_{n} W_{t}\right)$ e logaritmo do comprimento total $\left(I_{n} L_{t}\right)$, para cada estação do ano dentro da sub-ärea E.

$B$ - Representação dos resultados do teste de Kramer aplicado aos coeficientes (b) e constantes (a) das regressões acima citadas, e do padrão geral obtido para a sub-área E.

$C$ - Variação dos pesos totais médios estimados para as classes de comprimento de $170 \mathrm{~mm}, 200 \mathrm{~mm}$ e $240 \mathrm{~mm}$, durante as estações do ano, para a sub-ärea E. 


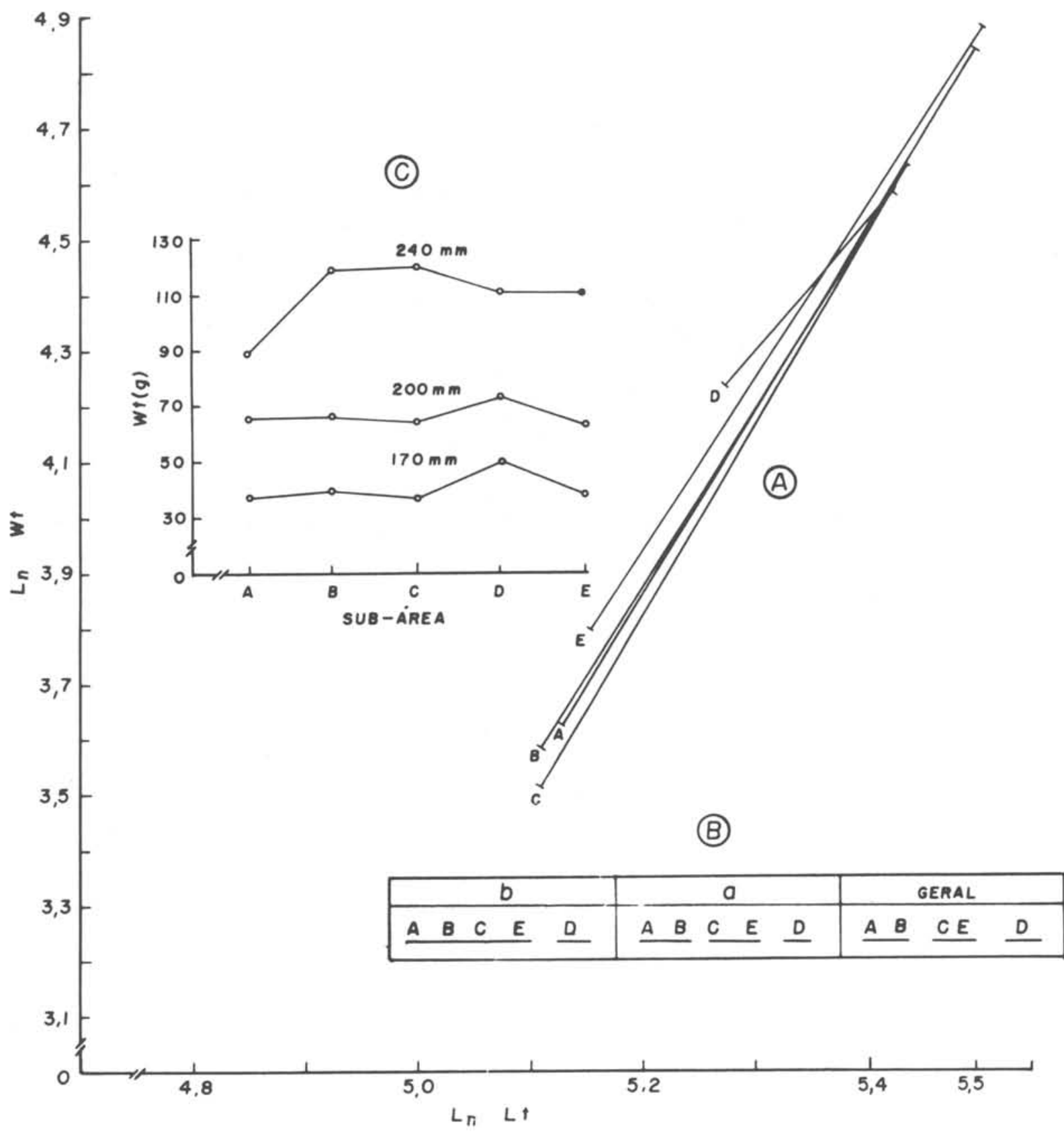

Fig. 11-A - Representação gräfica das retas de regressão entre logarítmo do peso total $\left(1_{n} W_{t}\right)$ e logarítmo do comprimento total $\left(l_{n} L_{t}\right)$, para cada uma das cinco sub-äreas consideradas, durante a primavera.

$B$ - Representação dos resultados do teste de Kramer aplicado aos coeficientes (b) e constantes (a) das regressões acima citadas, e do padrão geral obtido para a primavera.

$C$ - Variação dos pesos totais médios estimados para as classes de comprimento de $170 \mathrm{~mm}, 200 \mathrm{~mm}$ e $240 \mathrm{~mm}$, nas cinco sub-äreas, durante a primavera. 
(C)

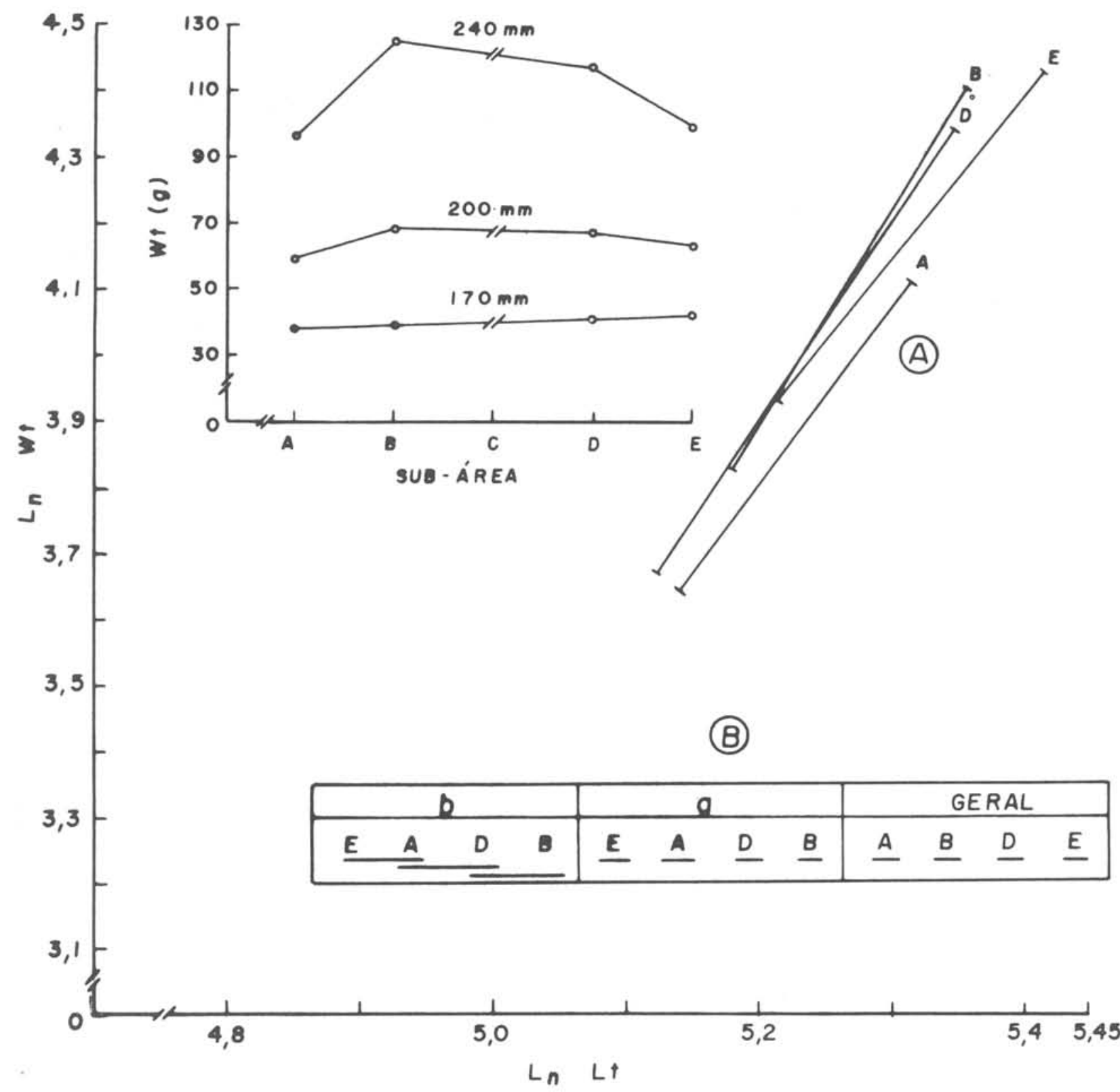

Fig. 12-A - Representação gräfica das retas de regressão entre logarítmo do peso total ( $\left.l_{n} W_{t}\right)$ e logarítmo do comprimento total ( $\left.l_{n} L_{t}\right)$, para cada uma das cinco sub-äreas consideradas, durante o verão.

$B$ - Representação dos resultados do teste de Kramer aplicado aos coeficientes (b) e constantes (a) das regressões acima citadas, e do padrão geral obtido para o verão.

C - Variação dos pesos totais médios estimados para as classes de comprimento de $170 \mathrm{~mm}, 200 \mathrm{~mm}$ e $240 \mathrm{~mm}$, nas cinco sub-äreas, durante o verão. 


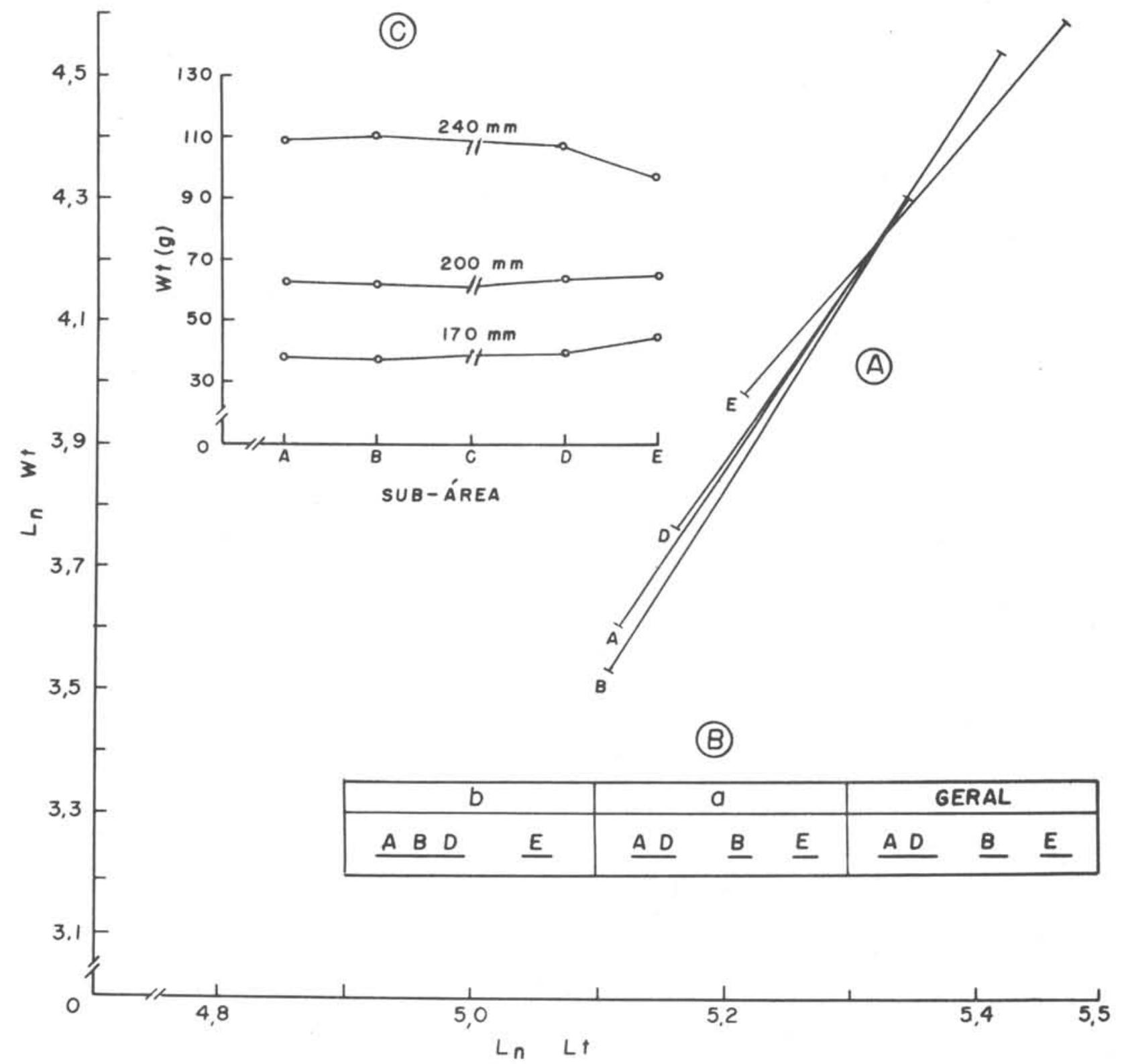

Fig. 13-A - Representação gräfica das retas de regressão entre logarítmo do peso total $\left(I_{n} W_{t}\right)$ e logarítmo do comprimento total $\left(I_{n} L_{t}\right)$, para cada uma das cinco sub-äreas consideradas, durante o outono.

$B$ - Representação dos resultados do teste de Kramer aplicado aos coeficientes (b) e constantes (a) das regressões acima citadas, e do padrão geral obtido para o outono.

C - Variação dos pesos totais mëdios estimados para as classes de comprimento de $170 \mathrm{~mm}, 200 \mathrm{~mm}$ e $240 \mathrm{~mm}$, nas cinco sub-äreas, durante o outono. 


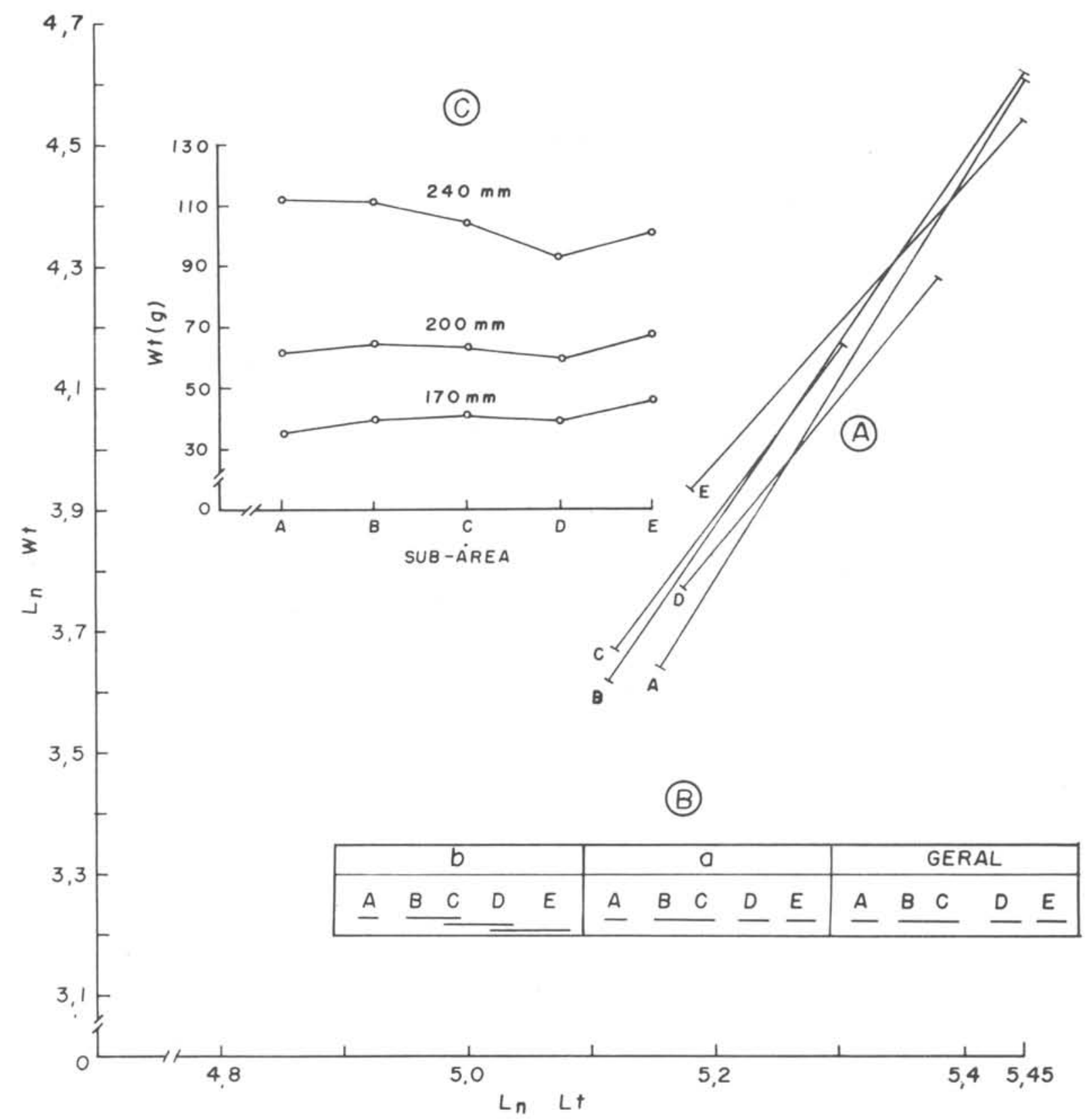

Fig. 14-A - Representação gräfica das retas de regressão entre logarítmo do peso total $\left(1_{n} W_{t}\right)$ e logarítmo do comprimento total $\left(l_{n} L_{t}\right)$, para cada uma das cinco sub-äreas consideradas, durante o inverno.

$B$ - Representação dos resultados do teste de Kramer aplicado aos coeficientes (b) e constantes (a) das regressões acima citadas, e do padrão geral obtido para o inverno.

C - Variação dos pesos totais mëdios estimados para as classes de comprimento de $170 \mathrm{~mm}, 200 \mathrm{~mm}$ e $240 \mathrm{~mm}$, nas cinco sub-äreas, durante o inverno. 
Sabendo que o peso è um parâmetro altamente influenciado por fatores intrỉnsecos (fisiológicos) e extrínsecos (ambientais), procurou-se estudar o processo de reprodução da espécie, que constitui un dos fatores que poderia estar agindo sobre a relação entre peso e comprimento dos indivíduos, determinando as variações observadas.

Da análise das distribuições de freqüência dos estádios de maturidade de fêmeas, por sub-ärea, durante as estações do ano, e para o período total (Tab. V) chegou-se aos seguintes resultados:

1) o aparecimento de maior número de fêmeas no estádio $C$ (maduro) ocorre na primavera e verão nas sub-āreas A e B, e na primavera, na sub-ärea D (Fig. 15);

2) as épocas de desova da espécie correspondem, portanto, às estações de primavera e verão nas sub-āreas A e B (de outubro a março), e de primavera na sub-área $D$, (de outubro a dezembro).

Os resultados fornecem também indicações quanto aos locais de desova da espécie, sendo um ao norte e outro ao sul da sub-área C (Fig. 15). Tal indicação é confirmada pelas freqüências de fêmeas C e D ao longo da ärea estudada; pode-se constatar, pela ocorrência de grande número de fêmeas $C$ (maduras) e logo a seguir D (desovadas) (Fig. 17), que a primeira ārea estā 1ocalizada entre $23^{\circ} \mathrm{S}$ e $25^{\circ} \mathrm{S}$, jā registrada através de estudos de distribuição e abundância de ovos e larvas (Matsuura, 1971) e a segunda área localizada entre $26^{\circ} \mathrm{S}$ e $28^{\mathrm{a}} \mathrm{s}$.

A Figura 15 evidencia alta concentração de indivỉduos jovens na sub-ärea $\mathrm{C}$ durante a primavera, outono e inverno. Tais indivíduos, na primavera e outono estão imaturos (A), entrando no inverno, no processo de maturação (B).

Durante dois verões seguidos (1971-1972), apesar de inümeras tentativas, não se conseguiu coletar nem indivỉduos jovens nem adultos nesta sub-ārea, pelo menos até a isóbata de $50 \mathrm{~m}$, profundidade máxima de captura por barcos de pesca.

Os resultados mostrados na Figura 16, forneceram indicações de movimentos de indivíduos de uma sub-ärea para outra. A ocorrência de indivỉduos no estádio A em elevada freqüência na sub-ärea C, e de indivíduos no estádio B nas sub-āreas A, B, D e E, sugere uma migração dos jovens para a sub-ärea C e dos indivíduos em maturação desta sub-área para as demais. 

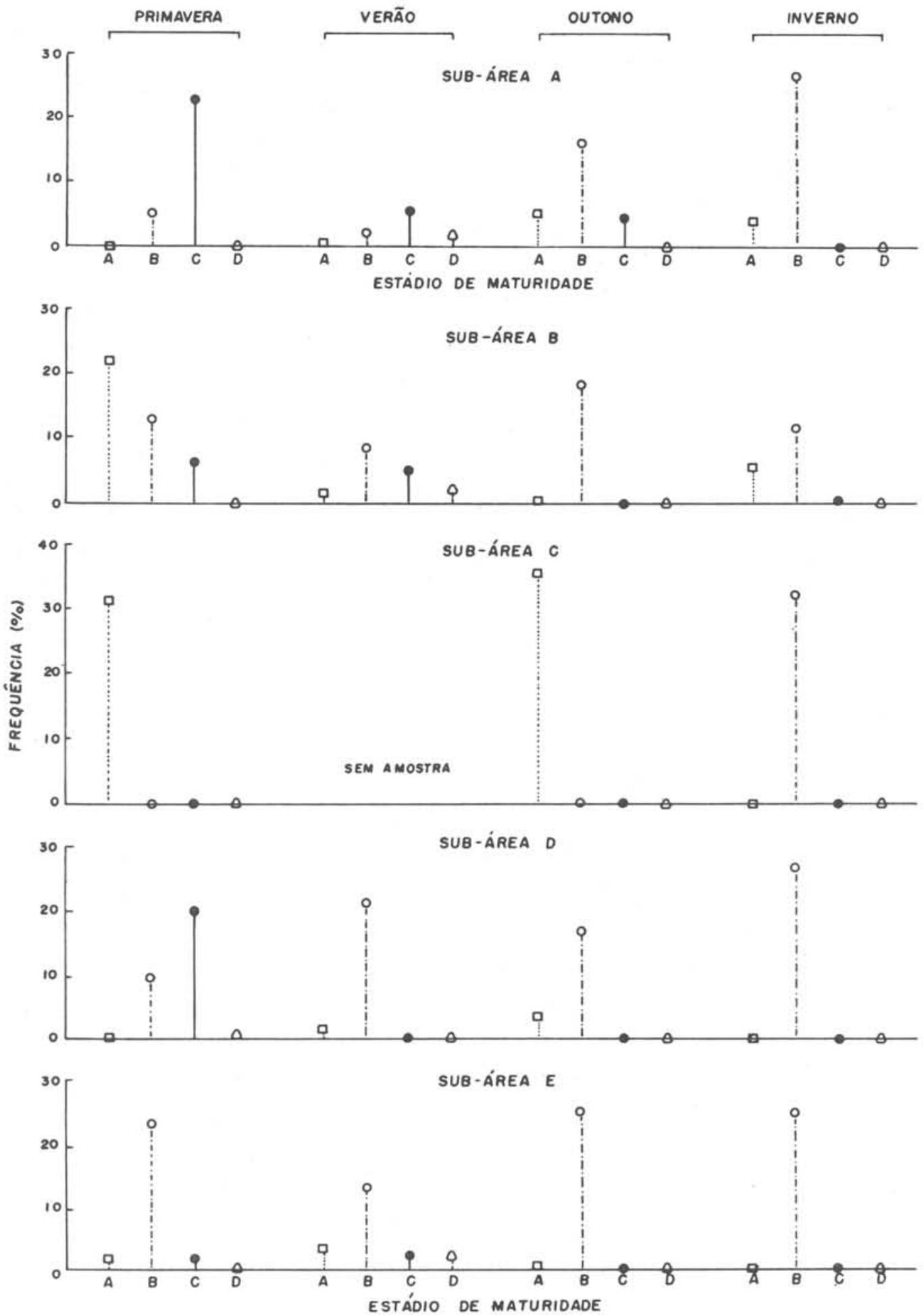

Fig. 15 - Representação gräfica das distribuições de freqüência relativa de ocorrência de fêmeas nos quatro estädios de maturidade, durante as estações do ano, em cada sub-ärea. 


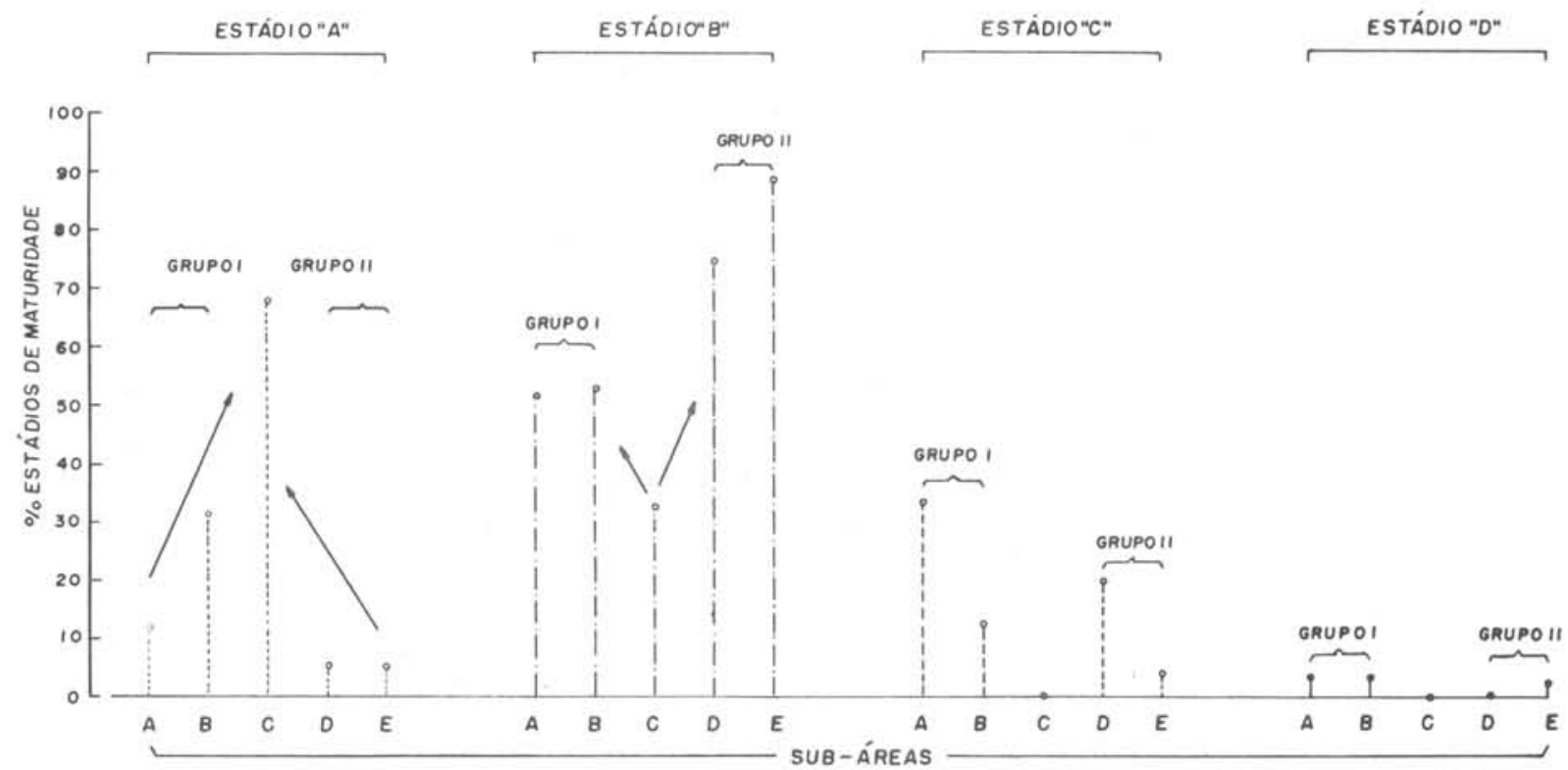

Fig. 16 - Representação gräfica das freqüências relativas de ocorrência de fêmeas nos quatro estädios de maturidade durante todo o período estudado, em cada sub-ärea considerada.

Indivíduos nos estādios C e D só foram encontrados nas sub-āreas A, B, D e E, provando ser aí os locais de reprodução da espécie, com deslocamento dos jovens, no estädio A para a sub-ärea C.

A inexistência de um padrão de variação na relação entre peso total e comprimento total para a espécie, entre as diversas sub-äreas e estações do ano, estaria então relacionada com a entrada e saîda de indivíduos nos diferentes estādios de maturidade, das e para as vārias sub-āreas estudadas.

Sabendo que o estádio de maturidade influi na relação peso total/comprimento total, procurou-se estabelecer uma relação entre a variação dos pesos totais médios, durante as estações do ano, dentro de cada sub-área, e as fases de desenvolvimento dos indivíduos. Analisadas as variações dos pesos para as classes de comprimento de $170 \mathrm{~mm}$ (iniciando o processo de maturação), $200 \mathrm{~mm}$ (adultos pequenos) e $240 \mathrm{~mm}$ (adultos grandes), resultou para $170 \mathrm{~mm}$ um peso de aproximadamente $40 \mathrm{~g}$; para $200 \mathrm{~mm}, 60 \mathrm{~g}$ e para $240 \mathrm{~mm}$ uma grande variação, mostrando que as diferenças encontradas para peso entre estações do ano são devidas principalmente aos indivíduos grandes $(240 \mathrm{~mm})$, correspondentes à parcela da população que participa ativamente do ciclo reprodutivo (Figs 6C-10C). 


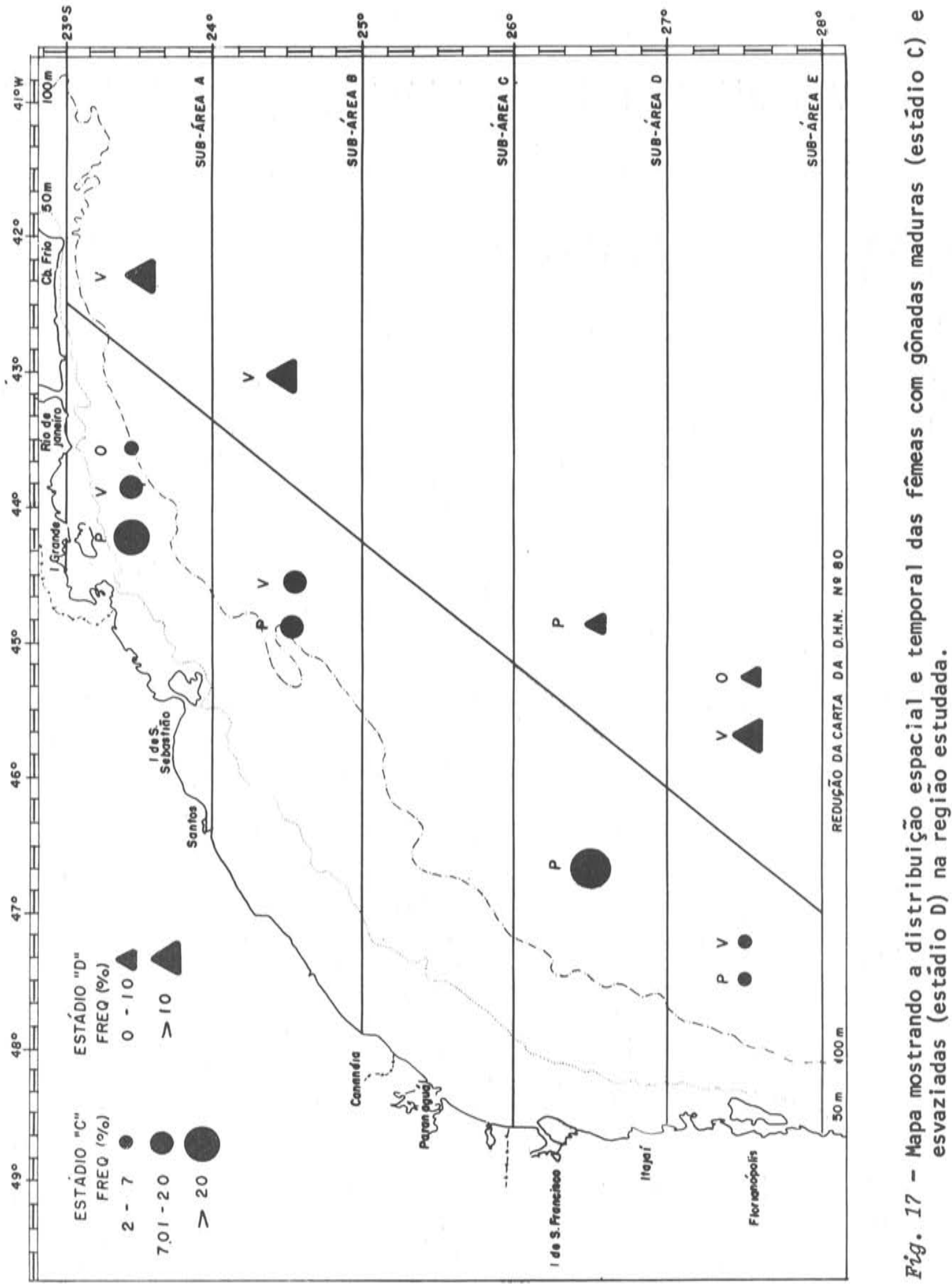


Entre sub-äreas (Figs 11C-14C) pode-se dizer que as oscilações em peso estão associadas à freqüência de aparecimento de indivíduos nos diversos estádios de maturidade.

Na primavera e verão, para a sub-ärea A, o peso dos adultos grandes foi mais baixo que nos meses de outono e inverno; estes indivíduos constituem a parcela da população que participa ativamente do ciclo reprodutivo. Para os que, estão iniciando o processo de maturação $(170 \mathrm{~mm})$ e adultos pequenos $(200 \mathrm{~mm})$, que ainda não participam ativamente do ciclo reprodutivo, os pesos mantiveram-se semelhantes durante o ano.

Para a sub-ārea B, ocorreram pesos mais elevados na primavera e verão, caindo durante o outono e inverno para os adultos grandes; os indivíduos em início de maturação e adultos pequenos quase não apresentaram variações sazonais em peso.

Na sub-ārea C, não houve praticamente variação em peso durante as estações para os que estão iniciando a maturação e adultos pequenos; para os adultos grandes $(240 \mathrm{~mm})$, o peso foi mais alto na primavera que no inverno.

Na sub-ārea D, o peso dos indivỉduos com 170 e $200 \mathrm{~mm}$ é alto na primavera, diminui no verão, permanecendo praticamente o mesmo durante o outono e inverno. Já para os indivỉduos de $240 \mathrm{~mm}$, o peso cresce da primavera para o verão, decrescendo a seguir no outono e inverno.

Na sub-ärea E, para aqueles que estão iniciando a maturação e adultos pequenos, não houve variações acentuadas em peso durante todo o ano, enquanto que para adultos grandes, o peso é máximo na primavera, decrescendo no verão e aumentando ligeiramente do outono para o inverno.

\section{DISCUSSÃO}

Constatou-se que Sardinella brasiliensis se agrupa em cardumes compostos por indivíduos com comprimentos totais abrangendo pequenas amplitudes de variação, o que ocorre comumente com os clupeídeos (Blaxter \& Holliday, 1963). Essa agregação uniforme quanto a classes de comprimento é provavelmente determinada pela ocorrência de desovas consecutivas. Sabemos que a espécie tem 
desova total (Vazzoler \& Rossi-Wongtschowski, 1976), mas que cardumes diferentes desovam em períodos distintos, dentro da época de desova (Besnard, 1950; Matsuura, 1971). Assim, cada cardume seria composto por indivíduos provindos de um grupo de desova.

Para peixes, a relação peso/comprimento pode apresentar ou não dimorfismo sexual. Hagerman (1952) encontrou em Microstomus pacificus fêmeas relativamente mais pesadas que os machos; Baxter (1960) não encontrou diferença significativa para a relação entre os sexos, em Seriola dorsalis; Talwar (1962) estudando a biologia de Hyporhomphus georgii encontrou para fêmeas $\log W=2,800 \log L-4,8156$ e para machos $\log W=1,667 \log L-2,2437$. Para Sebastolobus altivelis, Best (1964) não encontrou diferenças significativas entre machos e fêmeas, quanto à relação W/L. Angelescu et al. (1958) não encontraram diferenças, na relação, entre machos e fêmeas da merluza argentina (Merluccius mertuccius hubbsi). Thomas (1968) calculou as curvas de peso/comprimento de Cynoscium nobilis em águas californianas e não encontrou diferenças entre sexos. Para Micropogon furnieri e Macrodon ancylodon de nossas águas, foi encontrada homogeneidade entre sexos para a primeira (Vazzoler, 1971) e diferenças na relação entre machos e fêmeas para a segunda, em algumas épocas do ano (Yamaguti, comunicação pessoal*).

Entre clupeídeos, Clark (1928) estudando a relação peso/comprimento de Sardina caemulea da California não encontrou diferenças entre sexos. Heldt (1956), para Clupea pilchardus do Mediterrâneo, encontrou teores maiores de gordura, implicando em pesos mais elevados, para machos. Leim (1957) analisando Clupea harengus das āguas do Atlântico canadense não encontrou diferença entre sexos.

Para Sardinella brasiliensis não foi constatada diferença significativa na relação peso/comprimento entre machos e fêmeas.

Como $j a ̄$ citado na Introdução, o valor de $b$ na expressão $W=a L^{b}$, varia em torno de 3,0 para diferentes espécies. Lozano (1948) obteve para Sardina pilchardus de vigo um valor de b igual a 3,0124; Larraneta \& Lopez (1957) constataram que para Sardina pilchardus da costa de Castelon, b è igual

* Yamaguti, N. - São Paulo, Instituto Oceanogräfico, 1974. 
3,124; Andreu \& Fuster de Plaza (1962) verificaram que para S. pilchardus da Espanha, o valor de b era de 3,1972; Humphreys (1966) obteve um valor de b igual a 2,71 para Clupea harengus de Newfoundland; Heald \& Griffits (1967) verificaram que para Sardinella anchovia da Venezuela oriental, o valor de b era 2,91. Para Sardinella da costa centro-sul do Brasil, Nomura (1962) encontrou um valor de b igual a 3,211.

Alēm de diferir entre espécies, o valor de b apresenta variação para uma mesma espécie, quando estimado em épocas diferentes. Assim, Ramalho (cit. in: Navaz \& Ramalho, 1952) encontrou para a sardinha portuguesa, em épocas distintas, valores de b de 3,3459 e 3,2782.

Vanstone \& Market (1968), para Oncorhynchus kisutchi, verificaram que o parâmetro $b$, na equação $W=a L^{b}$, apresenta geralmente valor de 3,2 , mas que durante o desenvolvimento, o parâmetro a decresce de 7,5 para 6,2.

No presente estudo constatou-se que Sardinella brasiliensis na região estudada apresentou, para indivíduos maiores que $165 \mathrm{~mm}$ de comprimento total, variação no valor de b entre estações do ano, numa mesma sub-ärea; ocorreram também variações de a.

Navarro (1927), para jovens de Sardinella aurita de Baleares, encontrou diferenças no crescimento em peso durante o ano; durante os meses de verão e outono essa espécie se desenvolve com grande rapidez, favorecida pela temperatura da água $\left(20^{\circ} \mathrm{C}\right.$ no outono) e alimentação abundante. Oliver (1951) encontrou para $S$. pilchardus no noroeste da Espanha, pesos mais elevados na segunda metade do ano. Fernandez \& Navarro (1952) para S. pilchardus de Santander encontraram peso mínimo em abril, crescendo notavelmente ao longo da primavera e verão. Para S. pilchardus de vigo, Oliver \& Navarro (1952a) constataram um peso mínimo no inverno, aumentando na primavera e verão, e mantendo-se alto e estacionário no outono. Oliver \& Navarro (1952b) encontraram variações estacionais e anuais de peso, para essa espécie em Baleares. Ben-Tuvia (1960), estudando a relação peso/comprimento para $S$. curita da costa de Israel, verificou que o peixe está na sua melhor condição nos meses de outono. Egglishaw (1970) estudando Salmo salar no estreito da Escócia constatou mudanças sazonais na relação peso/comprimento: durante a estação de crescimento (maio-setembro) a média de peso para peixes com $50 \mathrm{~mm}$ foi $1,42 \mathrm{~g}$, em novembro $1,26 \mathrm{~g}$ e em janeiro caiu para $1,13 \mathrm{~g}$. Em março os peixes começaxam a aumentar de peso sendo que a média deste foi de 1,30 $\mathrm{g}$. 
Alēm das variações sazonais constatadas para $S$. brasiliensis de nossa costa, verificou-se que durante uma mesma estação do ano ocorreu variação na relação peso/comprimento entre as vārias sub-äreas.

Analisando tais variações verifica-se que ocorre homogeneidade para os valores de b entre algumas estações dentro de cada sub-ārea, e entre subáreas em uma mesma estação do ano, sugerindo que b (a taxa de incremento em peso) è um parâmetro específico (genético) que não varia acentuadamente em função de processos metabólicos e fatores ambientais. Já, analisando as variações da constante a, verifica-se que os seus valores são altamente variáveis, diferindo de estação para estação do ano, dentro de cada sub-área e entre sub-äreas durante cada estação. Este fato permite supor que as influências de fatores intrínsecos e extrínsecos são mais acentuadas sobre essa constante, a qual refletiria variações fisiológicas dos indivíduos em função do meio ambiente. Da interação entre os valores de b e a resultaram variações em peso para indivíduos das diferentes sub-äreas durante as estações do ano, não permitindo o estabelecimento de um padrão de variação para a relação W/L.

Navarro (1927), para S. aurita adulta, encontrou variações individuais em peso muito acentuadas em exemplares de mesmo tamanho; quanto maior era o comprimento, maiores diferenças ocorriam nos pesos; correlacionou estas diferenças com a fase de desenvolvimento sexual e quantidade de gordura visceral. Muzinic (1954), em exemplares pequenos de S. pilchardus que não tinham completado um ano de existência, quase não encontrou gordura, relacionando este fato ao intensivo crescimento dos jovens nessa época.

Para S. brasiliensis também constatou-se que ocorre maior dispersão dos valores de peso para as classes de comprimento mais elevadas.

0 estágio de desenvolvimento, na maioria dos peixes, parece ser causa importante na variação do peso. Le Cren (1951) encontrou para Perca fluviatilis relações diferentes entre peso e comprimento para os sucessivos estágios de desenvolvimento. Ananiades (1951), para S. aurita das águas gregas, observou um aumento do peso em função do crescimento em comprimento; entre 126-234 mm, o peso aumenta numa potência de 2,8 do comprimento, enquanto que entre 243-275 mm o peso aumenta numa potência de 3,4 do comprimento. Para Laskarides (1948) a relação peso/comprimento da sardinha grega não è a mesma 
em todos os estágios de desenvolvimento: nos jovens, entre 100-110 mm, o ganho relativo em peso é rāpido, seguindo-se um decrēscimo; a relação aumenta novamente em espécimes maiores de $160 \mathrm{~mm}$. Este fenômeno, segundo o autor, estaria relacionado à maturidade sexual e acúmulo de gordura nos estágios mais velhos. Para Gadus merlangus, das águas de Manx, Nagabhushanam (1964) encontrou claramente duas relações: para peixes imaturos, da ārea de criação, a relação foi $W=0,0074 L^{3,002}$ e para adultos de mar aberto $W=$ $0,0024 L^{3,346}$, sendo os b estatisticamente diferentes para as duas fases e āreas.

As relações peso/comprimento, no presente estudo, foram calculadas considerando-se apenas indivíduos que jā estavam iniciando a primeira maturação sexual, não permitindo assim discutir as variações em peso durante todas as fases de desenvolvimento.

Segundo Blaxter \& Holliday (1963) a primeira maturação só se inicia quando os indivíduos atingem um comprimento crítico, sendo que as distintas fases de maturação requerem um dado conteúdo em gordura para se processar; este comprimento crítico tem base genética e varia entre diferentes raças (por exemplo, arenques atlanto-escandinavos desovam com um comprimento maior que o de outras raças e também atingem um comprimento máximo mais elevado). Para $M$. furmieri da região entre $23^{\circ} \mathrm{S}$ e $33^{\circ} \mathrm{S}$, Vazzoler (1971) encontrou resultados semelhantes: as duas populações que aí ocorrem apresentam comprimentos médios de início da primeira maturação sexual, velocidades de maturação, taxas de crescimento e $L_{\infty}$ distintos.

Para S. brasiliensis da região estudada encontrou-se um mesmo valor para o comprimento médio em que se inicia a primeira maturação sexual para todas as sub-āreas; entretanto, o comprimento no qual $100 \%$ dos indivỉduos atingiram a maturação sexual, em cada sub-ārea não foi o mesmo. Após o início da primeira maturação, a velocidade com que o processo se completa, em cada sub-ārea, foi diferente, sendo de modo geral, mais elevada nas sub-āreas D e E.

0 fator de condição do peixe varia em completa conformidade com seu peso (Rudakova, 1959). Vazzoler \& Vazzoler (1965), estudando o fator de condição da sardinha desembarcada em Santos, mostraram existir uma variação distinta dos valores desse fator para peixes imaturos (até $180 \mathrm{~mm}$ ), maduros pequenos 
(180-200 mm) e maduros grandes (maiores de $200 \mathrm{~mm}$ ), durante o ano. No presente estudo constatou-se pequena variação em peso para indivíduos iniciando a maturação e adultos pequenos durante o ano, enquanto que essas variações são bem nỉtidas e acentuadas para os adultos grandes.

Mudanças no conteúdo em gordura, relacionadas ao estádio de maturidade têm sido intensamente estudadas. Le Cren (1951) mostrou que para Perca fluviatilis, a condição varia muito mais nas fêmeas maduras que nas imaturas, devido ao desenvolvimento dos produtos gonadais que levam a uma perda em peso. Botha (1971), para duas espécies de Merluccius, mostrou que a condição dos indivíduos é pobre durante o período de desova.

Para os clupeídeos é extensa a bibliografia que trata das mudanças no conteúdo em gordura relacionadas ao estádio de maturidade. Clark (1928) constatou que o conteúdo em óleo, em Sardinops caerulea, depende do tamanho e da condição sexual do peixe: peixes pequenos e imaturos e peixes grandes próximos da maturidade sexual, tem pouco óleo quando comparados com peixes grandes entre estações de desova. Andreu \& Rodrigues-Roda (1951) verificaram em $S$. aurita um antagonismo entre a curva representativa de atividade sexual e a de acúmulo de matérias graxas. 0 mesmo foi constatado para Sardinelza da área aqui considerada, por Vazzoler \& Vazzoler (1965). Muzinic (1954), em Sardina pilchardus do Alriätico oriental, verificou que a quantidade de gordura peri-intestinal na sardinha adulta variava no decorrer do ano: é pequena no fim da desova, aumentando depois, no curso da estação de pesca, sendo que o decréscimo na quantidade dessas reservas coincide com o desenvolvimento sexual. Este autor cita Fage (1920) que encontrou, para a sardinha da costa mediterrânea francesa, coincidências na queda do teor em graxas com o início da evolução gonadal. Fage (op. cit.) verificou também que a diminuição sensível das reservas em graxas, no início da evolução sexual, se manifesta somente nos indivíduos que apresentam um estádio de maturidade mais evoluido e como tal tomarão parte ativa na próxima postura. Bas \& Morales (1951) para Sardina pilchardus presumiram a existência de uma relação entre a ausência de qualquer depósito de gordura visceral e o apogeu da atividade gonadal. Heldt (1956), para Clupea pilchardus, assinala que a proporção de graxa é mais elevada nos indivíduos maiores; os valores mais baixos aparecem no fim da atividade sexual. 
Assim, tanto o teor de gordura, como as variações em peso podem fornecer indicação da época da desova. Fairbridge (1951) estudando a condição de Neoplatycephalus macrodon encontrou, para fêmeas, os valores mais altos no fim do inverno e começo da primavera, quando as gônadas estão em recuperação; quando elas crescem rapidamente durante o verão, a condição cai e atinge um mínimo depois que a desova terminou, individualmente. Este mínimo coincide com os mínimos de pesos totais. Fernandez \& Navarro (1952), para a sardinha de Santander, encontraram para cada comprimento, peso mínimo em abril, aumentando notavelmente ao longo da primavera e verão; o aumento em peso e abundância de gordura visceral variaram inversamente ao estado de maturação sexual; no verão (repouso gonadal) ocorreram os valores máximos de gordura. P1anas \& Vives (1952) não encontraram uma relação muito precisa entre a perda de reservas e desova em Sardina pilchardus, pois, no mês de postura, ao lado de indivíduos com baixo teor de gordura, foram encontrados exemplares com conteúdo graxo elevado. Leim (1957) mostrou que Clupea harengus da costa atlântico-canadense, tem um conteúdo mínimo de gordura em abril-maio (verão) e um máximo em julho-agosto (outono); os desovantes outonais mostram um rápido decréscimo no conteúdo de gorduras. Rudakova (1959) estudando Clupea harengus do Atlântico Norte europeu e mares adjacentes observou um evidente acúmulo de gordura nos órgãos internos a partir de maio, aumentando nos meses seguintes; observação visual mostrou uma redução lenta na gordura visceral em setembro-outubro e uma queda abrupta no período de desova (fevereiro-março) em todos os grupos de tamanho. Val et al. (1962) estudando variações estacionais na composição química de Sardina pilchardus mediterrânea e atlântica, encontraram, para o Atlântico, um mínimo de graxa coincidindo com a época de desova. Segundo Rudakova (op. cit.) o coeficiente de gordura é consideravelmente mais alto no período de prē-desova que no de pós-desova, explicando a mudança em peso como conseqüência dos gastos em função do desenvolvimento dos produtos sexuais.

Para S. brasiliensis, constatou-se que nas äreas que constituem locais de desova, os indivíduos que integram a parcela da população adulta, que participa ativamente da reprodução (os adultos grandes), apresentam variações sazonais no peso relacionadas à fase do processo de maturação em que se encontra a maior parte dos indivíduos da população; isso ocorre tanto para os indivíduos que desovam no norte $\left(23^{\circ} \mathrm{S}-25^{\circ} \mathrm{S}\right)$ durante a primavera-verão, 
como para os que desovam no sul $\left(26^{\circ} \mathrm{S}-28^{\circ} \mathrm{S}\right)$, durante a primavera. Dentro da ārea de desova norte, Matsuura (1971) constatou que o maior volume de desova ocorre na região da Ilha Grande; essa região localiza-se na sub-área A, onde as variações em peso são bem estabelecidas: o peso é mais elevado durante os meses de inverno (pré-desova), cai durante a primavera-verão (desova), elevando-se novamente durante os meses de outono (pós-desova).

Navaz \& Navarro (1952) condicionaram a variação do peso durante o ano com a maturidade sexual, grau de engorda e alimento em Sardina pilchardus. Já Furnestin (1943) não admite uma relação entre o teor de graxa e a desova para esta espécie, considerando que o acúmulo de graxa é mais dependente das condições de alimentação que do estado fisiológico do peixe. Fernandez \& Navarro (1952), para S. pilchardus de Santander, encontraram um mínimo invernal no conteúdo em graxas refletindo condições desfavoráveis de alimento e ambiente. Entretanto, Rudakova (1959) estudando Clupea harengus do mar do Norte europeu, encontrou um peso mínimo durante o período de alimentação intensa.

Segundo Blaxter \& Holliday (1963) os clupeídeos, de modo geral, são comedores sazonais, fabricando grandes estoques de gordura para sustentar-se quando o suprimento de alimento é pobre. As mudanças no teor de gordura do arenque em relação a alimento, idade, tamanho, raça e estádio de maturidade têm sido muito estudadas (Wood, 1958). Estudos realizados com S. pilcharcus (Hickling, 1945), mostraram que os picos de plâncton de primavera e outono provêem, potencialmente, alimento rico, mas se o peixe supre-se ou não deste alimento, depende, em larga escala da condição de suas gônadas, sendo que peixes com gônadas desenvolvidas comem muito pouco. 0 arenque que desova no outono, alimenta-se e acumula reservas em maio e junho, cessando a alimentação e perdendo gordura em junho e agosto (outono). Após desovar volta a alimentar-se e a acumular reservas cada vez mais, sendo que, durante o inverno (com pouco alimento) atinge o conteúdo mais baixo em reservas. Nos arenques desovantes de inverno e primavera, as boas condições alimentares no fim da primavera e começo do verão (após desova) fazem aumentar as reservas de gordura; com o desenvolvimento das gônadas no fim do outono, a alimentação cessa e ocorre desova de dezembro a março (inverno). Val et al. (1962) observaram que em $S$. pilchardus atlântica o máximo em gorduras verifica-se exatamente quando também é máxima a quantidade de fitoplâncton (setembro); 
para a mesma espécie no Mediterrâneo ocorre um mäximo conteüdo graxo no mês de maio, sendo que a postura tem lugar de janeiro a março; existe então notável coincidência da mesma com o máximo de gorduras.

Para a sardinha brasileira, Furuya (1959) encontrou oscilações sazonais do teor de matéria graxa de março a maio (período que corresponde a pósdesova), existindo um minimo em gordura de novembro a fevereiro (que corresponde ao período de desova); o prōprio autor faz uma crítica à curva de flutuação do teor de gordura apresentada, dizendo que não deveria ter sido ignorada a diferença no estado de desenvolvimento dos peixes. Os resultados obtidos por Furuya (op. cit.) foram confirmados por Watanabe (1963). Vazzoler \& Vazzoler (1965) relacionaram a curva do teor de gordura obtida por Watanabe (op. cit.) com a de variação do fator de condição mostrando haver um paralelismo entre ambas, com certa defazagem no tempo.

Na ārea estudada, segundo Teixeira e Aidar-Aragão* (comunicações pessoais) a sub-área c é possivelmente a de mais elevada produtividade na costa do Brasil, predominando no plâncton diatomáceas grandes, ricas em óleo. Já as sub-āreas A e B, têm baixa produtividade, sendo que na região de Cabo Frio ela é dez vezes menor que na região de Paranaguá, predominando no plâncton fitoflagelados pobres em óleos.

Os altos pesos encontrados nas sub-äreas $\mathrm{D}$ e $\mathrm{E}$ e a maior velocidade de maturação total (100\%) nestas duas sub-äreas estariam relacionadas então ao nível mais elevado de suprimento de alimento.

Como visto, as variações em peso e teor de gordura estão relacionadas entre sí e dependem da interação de processos metabólicos (transformação dos alimentos, reprodução etc) e fatores ambientais, tanto biótico (disponibilidade de alimento) como abióticos (correntes, temperatura, salinidade etc). A variação dos fatores ambientais e as exigências metabólicas determinam os aspectos comportamentais da espécie.

O comportamento dos clupeídeos foi estudado, entre outros, por Blaxter \& Holliday (1963), Muzinic (1973), Skrivanic \& Zadovinic (1973), principalmente sob o aspecto de migrações, mostrando complexidade em relação a vários fatores como luz, temperatura, alimento e reprodução. Como as migrações são * Teixeira, C. e Aidar-Aragão, E.-São Paulo, Instituto Oceanogrä́ico, 1974. 
controladas não se sabe; ciclos de atividade hormonal sugerem que hã um ciclo de secreção endócrina que faz com que os peixes "tenham urgência" em migrar. A questão estā em saber se este ciclo é só endogeno ou sofre influência ambiental (luz, comprimento do dia, correntes etc). A migração se faz em rotas bem estabelecidas. Hā evidência de agregação de clupeídeos em āreas bem definidas, parcialmente controladas por massas de água e parcialmente como resultado de processo ativo, orientado pelo peixe. Segundo Blaxter \& Holliday (op. cit.) para o arenque, parece haver uma deriva com uma corrente residual apōs desova e um movimento mais direto, em direção às áreas de desova, efetuado por migração contranatante.

Muzinic (op. cit.) estudando a migração de $S$. pilchardus adultas no Adriātico, através de marcação, mostrou que ocorrem duas migrações (ou pelo menos dois picos de uma migração contínua) do centro do Adriático para áreas costeiras: uma na primavera e outra no fim do verão, começo do outono, sendo que ambas são incompletas, pois a captura em mar aberto continua, e parecem ter causas distintas. A da primavera ocorre com peixes no fim da desova, exaustos, após um longo período de desova e mostrando baixo teor de gorduras - parece ser uma migração trófica; esta hipótese é sustentada por um rápido aumento no conteúdo em gorduras e no fator de condição. A segunda migração coincide com o início da maturação sexual, alto conteūdo em gordura e alto valor do fator de condição. Esta migração dos adultos grandes, verifica-se no fim do outono, coincidindo com o aparecimento de estádios de maturidade avançados e grande número de ovos no plâncton: é obviamente uma migração reprodutiva. Skrivanic \& Zadovinic (1973), tambēm estudando migrações das sardinhas do Adriātico, verificaram que há migrações de adultos para áreas definidas no centro do Adriātico, no final do período de maturação; aí ocorre a desova e apōs esta, pós-larvas e peixes migram em direção oposta, para āreas de alimentação localizadas na costa. Zij1stra (1961) admite para o arenque do Mar do Norte a existência de um sentido de "volta a casa". A habilidade dos desovantes de retornarem aos lugares onde nasceram faz pensar numa "memōria" mais desenvolvida do que nos salmonídeos, ou existe a possibilidade dos mais novos seguirem os mais velhos (Blaxter \& Holliday, 1963).

Richardson \& Sadowski (1960) levantaram a hipótese de uma possível migração das sardinhas de Cananéia para o Rio de Janeiro. Dentro da região 1a- 
gunar de Cananéia encontraram dois grupos: um que aparecia em outubro (primavera) e deixava a região em maio (outono) ou um pouco mais tarde e um segundo grupo, numericamente mais pobre, que começava aparecer em abril (outono). De acordo com estes autores, os dois grupos seriam separados tanto geograficamente como pelo seu período de desova; o primeiro seria encontrado ao sul e o segundo ao norte de Cananéia. Ao norte existiria ainda um estoque residual composto por grupos mais velhos ou possivelmente outras populações.

Richardson et al. (1959) estudando a composição em comprimento e idade de Sardinella desembarcadas em Santos e Rio de Janeiro, verificaram que, após fevereiro, no Rio de Janeiro há aumento na média de comprimento por idade, que continua atē abril (outono). Para os peixes de três anos de idade, encontraram diferenças em comprimento entre Rio de Janeiro e Santos, com tamanho reduzido para a idade, em Santos; não souberam a que atribuir essa diferença: se à existência de dois estoques ou se à amostragem de uma população migrante na ārea de Santos.

No presente trabalho confirma-se a existência de dois grupos, com épocas e locais de desova distintos. Associando os grupos aqui identificados aos sugeridos por Richardson \& Sadowski (1960) tem-se que o segundo grupo destes autores constitui o grupo das sub-āreas A e B $\left(23^{\circ} \mathrm{S}-25^{\circ} \mathrm{S}\right)$, e o primeiro grupo o das sub-äreas D e E $\left(26^{\circ} \mathrm{S}-28^{\circ} \mathrm{S}\right)$. A sub-ärea C $\left(25^{\circ} \mathrm{S}-26^{\circ} \mathrm{S}\right)$ constituise num criadouro para onde se dirigem os jovens dos dois grupos, em busca de condições alimentares favoráveis a seu crescimento (deslocamento trófico) e que, ao atingirem o estágio de pré-desova (indivíduos no estádio B que aí ocorrem no inverno), retornam para seus locais de origem (deslocamento reprodutivo). Em Santos tem-se uma ārea de franca migração: os peixes provenientes de Cananéia estariam alcançando esta área no outono, com o comprimento de 18-19 cm (três anos para Richardson et al., op. cit.).

Pode-se concluir portanto que, as variações existentes na relação peso/ comprimento de Sardinella brasiliensis dentro da ārea estudada, são devidas a movimentos de peixes em diferentes fases de maturidade e condição de uma sub-ārea para outra.

Apesar de verificar-se desova diferencial (épocas e locais distintos) entre os dois grupos, a ocorrência de jovens de ambos os grupos, na sub-área 
C, apesar de aí penetrarem em épocas distintas, deixa em aberto a possibilidade de mistura entre ambos.

A continuidade deste estudo, analisando proporções corporais e caracteres merísticos de $S$. brasiliensis da ārea considerada, poderá vir a contribuir para a elucidação desta questão.

\section{CONCLUSÕES}

0 presente estudo permite concluir que:

1 - Sardinella brasiliensis agrega-se em cardumes constituídos por indivíduos apresentando pequena variação em seus comprimentos totais;

2 - a relação entre peso total e comprimento total é expressa por uma equação do tipo $y=a+b x$ para cardumes isolados, e por uma equação exponencial, do tipo $y=a x^{b}$, para o todo, sendo que as retas representativas da relação para cada cardume integram a curva geral para a espécie;

3 - os parâmetros $b$ e a da equação $W_{t}=a L_{t}^{b}$, apresentam variações entre estações do ano dentro de cada sub-ārea estudada, e entre sub-āreas dentro de cada estação do ano, sem mostrar um padrão de variação definido dentro da ārea total;

4 - a interação entre estádio de maturidade, deslocamentos e condições de suprimento de alimento, determina a ausência de um padrão de variação para a relação peso/comprimento;

5 - não ocorre dimorfismo sexual quanto a relação peso/comprimento para a espēcie estudada;

6 - após o início da primeira maturação sexual, a velocidade de maturação, nas diversas sub-äreas, se diferencia, sendo mais elevada entre $26^{\circ} \mathrm{S}$ e $28^{\circ} \mathrm{S}$;

7 - ocorre desova em locais e épocas distintos: entre $23^{\circ} \mathrm{S}$ e $25^{\circ} \mathrm{S}$, durante a primavera e verão, e entre $26^{\circ} \mathrm{S}$ e $28^{\circ} \mathrm{S}$, durante a primavera;

8 - a relação peso/comprimento está inteiramente associada ao estádio 
de maturidade dos indivíduos; este relacionamento é mais nítido para os adultos grandes, que participam ativamente do ciclo reprodutivo;

9 - a região entre $25^{\circ} \mathrm{S}$ e $26^{\circ} \mathrm{S}$, constitui-se num criadouro para os jovens que aí chegam na primavera e outono;

10 - a espécie realiza dois tipos de deslocamentos: um trófico, em direção à área de criação, realizado pelos jovens e outro reprodutivo para as āreas de desova, realizado pelos adultos.

\section{AGRADECIMENTOS}

Agradeço aos Drs. Anna Emília A. de M. Vazzoler e Paulo Emílio Vanzolini pela orientação, incentivo e dedicação constantes durante todo este trabalho.

Ao Instituto Oceanográfico da Universidade de São Paulo pelo auxílio financeiro nas viagens de coleta, franquia de suas instalações, 1aboratórios, bases de pesquisa e colaboração de seu pessoal técnico.

A Fundação de Amparo à Pesquisa do Estado de São Paulo (FAPESP) pela bolsa concedida.

A Oscar Barbosa e Wilson Ribas pela colaboração na coleta de amostras e nos trabalhos de laboratório.

Aos Drs. Gelso Vazzoler, Noriyoshi Yamaguti e Yasunobo Matsuura pelas sugestões e discussões durante a elaboração deste trabalho.

Ao Serviço de Extensão da Pesca de Santa Catarina (ACARPESC), ao Sr. Maurilio Dal Grande Borges, DD. Delegado da SUDEPE em Itajaí, à Diretoria da INTERPESCA de Itajaí, aos funcionários da Base de Pesquisas Oceanográficas da SUDEPE em Paranaguá, pelo esforço na coleta de amostras e gentileza na acolhida.

À Alfredo Martins Paiva Filho pela elaboração da programação e execução de parte da análise estatística dos dados, efetuada no Computador B-3.500 do Centro de Computação Eletrônica da Universidade de São Paulo.

À Srta. Lucy Teixeira pelo auxílio na padronização das citações bibliogräficas. 


\section{BIBLIOGRAFIA}

ANADON, E. 1954. Estudios sobre la sardina del noroeste español. Pub1nes Inst. Biol. ap1., Barcelona, 18:43-106.

ANANIADES, C. I. 1951. Quelques considerations biometriques sur 1'allache (Sardinella carita C. et V.) des eaux grecques. Praktika e11. 'udrobio1. Inst., 5(1):24-26.

ANDREU, B. \& RODRIGUES-RODA, J. 1951. Estudio comparativo del ciclo sexual, engrasamiento y repleción estomacal de la sardina, alacha y anchoa de1 mar Catalán, acompañado de relaciōn de pescas de huevos planctonicos de estas especies. Publnes Inst. Biol. ap1., Barcelona, $9: 209-229$.

\& FUSTER DE PLAZA, M. L. 1962. Estudio de la edad y crecimiento de la sardina (Sardina pilchardus Walb.) del NW de España. Investigación pesq., 21:75-78.

ANGELESCU, V.; GNERI, F. S. \& NANI, A. 1958. La merluza de1 mar argentino. (Biologia e Taxonomia). Argentina, Secr. Mar., Serv. Hidrogr. Nav., H 1004:81-93.

BAS, C. \& MORALES, E. 1951. Nota sobre 1a talla y la evolución sexual de las sardinas de la Costa Brava (septiembre de 1949 a septiembre de 1950). Publnes Inst. Bio1. ap1., Barcelona, 8:169-180.

BAXTER, J. L. 1960. A study of the yellowtail Seriola dorsalis (Gil1). Fish Bull. Calif., (110):32-35.

BELL, R. R. 1964. Weight-length relationship for bluefin tuna in the California fishery, 1963. Calif. Fish Game, 50(3):216-218.

BEN-TUVIA, A. 1960. Synopsis of biological data on Sardinella aurita of the Mediterranean Sea and other waters. F.A.0. Fish. Biol. Synopsis, (14) : 289-311.

BESNARD, W. 1950. Nota preliminar sobre uma particularidade da biologia de Sardinella aurita Cuv. \& Val., da costa brasileira. Bolm Inst. paul. Oceanogr., 1(1):69-79.

BEST, E. A. 1964. Spawning of longspine channel rockfish, SebastoZobus altivelis Gilbert. Calif. Fish Game, 50(4):265-267.

BLACKBURN, M. 1950. Studies on the age, growth and life history of the pilchard, Sardinops neopilchardus (Steindachner), in Southern and Western Australia. Aust. J. mar. Freshwat. Res., 1(2):250-251.

BLAXTER, J. H. S. \& HOLLIDAY, F. G. T. 1963. The behaviour and physiology of herring and other clupeids. In: Russe11, F. S., ed. Advances in marine biology. London, Academic Press, 1:261-393. 
BOTHA, L. 1971. Growth and otolith morphology of the Cape Hakes MerZuccius copensis Cast. and $M$. paradoxus Franca. Invest1 Rep. Div. Sea Fish. Un. S. Afr., (97):6-10.

BROWN, M. E. 1946. The growth of brown trout (Salmo trutta Linn.). II. The growth of two-year-old trout at a constant temperature of $11.5^{\circ} \mathrm{C}$. J. exp. Biol., 22:130-144.

CLARK, F. N. 1928. The weight-length relationship of the California sardine (Sardina caerulea) at San Pedro. Fish Bull. Calif., (12):5-59.

1934. Maturity of the California sardine (Sardinops caemilea) determined by ova diameter measurements. Fish Bull. Calif., (42) :1-49.

DEBROSSES, P. 1933. Etude de la sardine de la côte de Bretagne depuis Concarneau jusqu' à 1 'embochure de la Loire. Revue Trav. Off. Pêch. marit., $6(1): 47-48$.

EGGLISHAW, H. J. 1970. Production of salmon and trout in a stream in Scotland. J. Fish Biol., 2(2):120-121.

FAGE, L. 1920. Engraulidae, Clupeidae. Rep. Dan. oceanogr. Exped. Mediterr., 2(19):1-140.

FAIRBRIDGE, W. S. 1951. The new south wales tiger flathead, Neoplatycephalus macrodon. Aust. J. mar. Freshwat. Res., 2(2):138-142.

FERNANDEZ, R. \& NAVARRO, F. de P. 1952. La sardina de Santander. Boln Inst. esp. Oceanogr., (55): 8-17.

FURNESTIN, J. 1943. Contribution à l'étude biologique de la sardine atlantique (Sardina pilchardus Walb.). Revue Trav. Off. Pêch. marit., $13: 221-341$.

FURUYA, M. 1959. Variação sazonal do teor de matéria graxa em sardinha verdadeira (Sardinella aurita). Nota preliminar. Bolm Inst. oceanogr., S Paulo, 10(3):21-24.

FUSTER DE PLAZA, M. L. \& BOSCHI, E. E. 1961. Estudio biologico pesquero de la anchoita (Engraulis anchoita) de Mar del Plata. Publnes Secr. Agric. Ganad. Repub. Argent., Dep. Investig. Pesq., 17:1-40.

HAGERMAN, F. B. 1952. The biology of the Dover sole, Microstomus pacificus (Lockington). Fish Bul1. Calif., (85):20-22.

HEALD, E. J. \& GRIFFITS, R. C. 1967. La determination por medio de la lectura de escamas, de la edad de la sardina, Sardinella anchovia, de1 Golfo de Cariaco, Venezuela Oriental. Série Recurs Explor. pesq., $1(10): 436-437$.

HELDT, H. 1956. Rapport sur la sardine "Clupea pilchardus" (Walb.). 
Rapp. P. -v. Réun. Commn int. Explor. scient. Mer Méditerr., n. s., $13: 125-126$.

HICKLING, C. F. 1945. The seasonal cycle in the Cornish pilchard. J. mar. bio1. Ass. U. K., 26:115-138.

HILE, R. 1936. Age and growth of the cisco Leucichthys artedi (Le Seur), in the lakes of the north-eastern highlands, Wisconsin. Bull. Bur. Fish., Wash., 48:211-317.

HUMPHREYS, R. D. 1966. Biological characteristics of a herring population on the South Coast of Newfoundland. J. Fish. Res. Bd Can., 23(6): 797-804.

ITO, Y.; SANCHES, L. \& SILVA, D. R. da 1969. Seasonal variation of the chemical composition of sardine. Contrções Inst. oceanogr. Univ. S Paulo. sér. Tecnol., (6):1-8.

JONES, A. N. 1970. A study of salmonid populations of the River Teify and tributaires near Tegraron. J. Fish Biol., 2(2):190.

KRAMER, C. Y. 1956. Extension of multiple range tests to group means with unequal numbers of replications. Biometrics, 12(3):307-310.

LARRAÑETA, M. G. \& LOPEZ, J. 1957. The growth of the Castelon coast sardine (Sardina pilchardus Walb.). Proc. tech. Pap. gen. Fish. Coun. Mediterr., (4):101-108.

LASKARIDIS, C. 1948. Study of the biology of the sardine (Clupea pilchardus Walb.) in greek waters. Praktika ell. 'udrobiol. Inst., 2(1): 83-87.

LE CREN, E. D. 1951. The length-weight relationship and seasonal cycle in gonad weight and condition in the perch (Perca fluviatilis). J. Anim. Eco1., 20(2):201-219.

LE GALL, J. 1930. Contribution à 1'étude de la sardine des côtes françaises de $1 \mathrm{a}$ Manche et de 1'Atlantique. 20 partie: 1a sardine des côtes de Bretagne. Revue Trav. Off. Pêch. marit., 3(1):57-58.

LEIM, A. H. 1957. Fatness of herring in Canadian Atlantic waters. Bu11. Fish. Res. Bd Can., (111):177-184.

LEME, R. A. da S. 1958. Curso de estatística. São Paulo, Escola Politécnica, vol. 2, (mimeo).

LOZANO, F. 1948. Notas sobre la biologia y biometria de la parrocha o sardina joven de Vigo. Boln Inst. esp. Oceanogr., (6).

MACGREGOR, J. S. 1957. Fecundity of the Pacific sardine (Sardinops caemilea). Fishery Bull. Fish Wildl. Serv. U.S., 57:427-499. 
MACGREGOR, J. S. 1959. Relation between fish condition and population size in the sardine (Sardinops caerulea). Fishery Bull. Fish Wild1. Serv. U.S., 60(166):215-230.

MARTIN, W. R. 1949. The mechanics of environmental control of body form in fishes. Publs Ont. Fish. Res. Lab., 70:1-91.

MATSUURA, Y. 1971. A study of the life history of Brazilian sardines, Sardinella aurita. I. Distribution and abundance of sardine eggs in the region of Ilha Grande, Rio de Janeiro. Bolm Inst. oceanogr., S Paulo, $20(1): 33-60$.

MONTES, M. L. A. de 1953. Notas sobre a alimentação de alevinos de sardinha verdadeira-Sardinella aurita Cuv. \& Val. Bolm Inst. oceanogr., S Paulo, 6(1/2):161-180.

MORAES, M. N. de 1963. Observações sobre a biologia da sardinha e sua captura ao longo da costa sul do Brasil de 1959-1961. Bolm Ind. anim., n.s., 21 (único) :3-16.

MUZINIC, R. 1954. Contribution à 1'étude de 1'oecologie de la sardine (Sardina pilchardus Walb.) dans l'Adriatique orientale. Acta adriat., $5(10): 73-79$.

1973. Migrations of adult sardines in the Central Adriatic. Neth. J. Sea Res., 7:19-30.

NAGABHUSHANAM, A. K. 1964. On the biology of the whiting, Gadus merZangus, in Manx Waters. J. mar. biol. Ass. U. K., 44:192-193.

NAVARRO, F. de P. 1927. Estudios sobre los clupeideos de Baleares. 2. La alaxta (Sardinella aurita C. y v.). Notas Resúm. Inst. esp. Oceanogr., sërie II, (21):9-14.

NAVAZ, J. M. \& NAVARRO, F. de P. 1952. Nuevas observaciones sobre 1a sardina del Golfo de Viscaya (1951) y consideraciones sobre la estadistica de pesca. Boln Inst. esp. Oceanogr., (54):7-10.

NIKOLSKII, G. V. 1969. Theory of fish population dynamics as the biological background for rational exploitation and management of fishery resources. Edinburg, Oliver \& Boyd, p. 68-86.

NOMURA, H. 1962. Length-weight tables of some fish species from Southern Brazil. Contrções Inst. oceanogr. Univ. S Paulo, série Oceanogr. biol., (2):1-4.

OLIVER, M. 1951. La sardina de la costa noroeste española en 1948 y 1949 (Estudo biométrico e biológico). Boln Inst. esp. Oceanogr., (42): $1-12$.

\& NAVARRO, F. de P. 1952a. Nuevos datos sobre la sardina de Vigo. Boln Inst. esp. Oceanogr., (56):25-39. 
OLIVER, M. \& NAVARRO, F. de P. 1952b. La alacha y la sardina de Baleares. Investigaciones en 1950 y 1951. Boln Inst. esp. Oceanogr., (58): $1-49$.

PHILLIPS, J. B. 1964. Life history studies on ten species of rockfish (Genus Sebastodes). Fish Bull. Calif., (126):5-70.

PLANAS, A. \& VIVES, C. 1952. Contribución al estudio de la sardina (Sardina pilchardus Walb.) del levante español (sectores de Vinaroz e Islas Columbretes). Publnes Inst. Biol. ap1., Barcelona, 10:36-37.

RAMALHO, A. 1936. Variation du poids moyen de 1a sardine. Trav. Stn Bio1. marit. Lisb., (36):1-2.

RICHARDSON, I. D. \& SADOWSKI, V. 1960. Note on the sampling of sardine (Sardinella allecia) at Cananéia, State of São Paulo, Brazil. Bolm Inst. oceanogr., S Paulo, 6(1):87-97.

; VAZZOLER, G.; FARIA, A. de \& MORAES, M. N. de 1959. Report on sardine investigations in Brazil. F. A. 0. Experience paper, (13) : 1051-1079.

RUDAKOVA, V. A. 1959. Data on the food of the Atlantic herring. Spec. scient. Rep. U. S. Fish Wild1. Serv., Fisheries, (327):140-165.

SANTOS, E. P. dos \& FRANTZEN, F. M. 1965. Growth of sardines - quantitative aspects. Anais Acad. bras. Cienc., 37(supl.):360-362.

SAVITZ, J. 1969. Effects of temperature and body weight on endogenous nitrogen excretion in the bluegill sunfish (Leponis macrochimus). J. Fish. Res. Bd Can., 26(7):1813-1816.

SCHAEFFER, M. B. 1952. Comparison of yellowfin tuna of Hawaiian waters and of the American west coast. Fish Bull. Calif., (72):358-359.

SKRIVANIC, A. \& ZAVODNIC, D. 1973. Migrations of the sardine (Sardina pilchardus) in relation to hydrographical condition of the Adriatic Sea. Neth. J. Sea Res., 7:7-18.

SKUD, B. E. 1955. Length-weight relationship in migrating fry of pink salmon (Oncorhynchus gorbuscha) in Saskin Creek, Little Port Walter, Alaska. Copeia, (3):204-207.

TALWAR, P. K. 1962. A contribution to the biology of the halfbeak, Hyporhamphus georgii (Cuv. \& Val.) (Hemirphamphidae). Indian J. Fish, sect. A, 9(1):190-192.

THOMAS, J. C. 1968. Management of the white seabass (Cynoscion nobilis) in California waters. Fish Bu11. Calif., (142):19-21.

TREMEL, E. 1967. Relatório das atividades do Centro de Pesquisas de Pesca apresentado ao Acordo de Pesca - 1966. Florianópolis, Centro de Pesquisas de Pesca. 20 D. 
TREMEL, E .; FRANTZEN, F. M. \& JONSSON, S. 1965. Relatörio sobre o estudo da sardinha em Santa Catarina, durante o ano de 1964. Florianópo1is, Centro de Pesquisas de Pesca, 22 p.

\& JONSSON, S. $1965 . \quad$ Relatório à SUDEPE das viagens de estudo da sardinha no Estado de Santa Catarina no período de junho-julho de 1964. Projeto Sardinha SUDEPE 5012/63. Florianópolis, Centro de Pesquisas de Pesca, 20 p.

VAL, M. J. del; COSTA, R. L.; MOLINS, L. R. \& BESADA, R. 1962. Variaciones estacionales en la composición de la sardina mediterranea y atlantica. Boln Inst. esp. Oceanogr., (107):1-12.

VANSTONE, W. E. \& MARKET, J. R. 1968. Some morphological and biochemical changes in coho salmon, Oncorhynchus kisutch during parr smolt transformation. J. Fish. Res. Bd Can., 25(11):2403-2418.

VAZZOLER, A. E. A. de M. 1962. Sobre a primeira maturação sexual e destruição de peixes imaturos. Bolm Inst. oceanogr., S Paulo, 12(2):5-38.

1971. Diversificação fisiológica e morfológica de Micropogon furnieri (Desmarest, 1822) ao sul de Cabo Frio, Brasil. Bolm Inst. oceanogr., S Paulo, 20(2):1-70.

\& ROSSI-WONGTSCHOWSKI, C. L. D. B. 1976. Sar dinella brasiliensis: tipo de desova, fecundidade e potencial reprodutivo relativo. I. Area entre $23^{\circ} 40^{\prime} \mathrm{S}$ e $24^{\circ} 20^{\prime} \mathrm{S}$, Brasil. Bolm Inst. oceanogr., S Paulo, 25(1):131-155.

\& VAZZOLER, G. 1965. Relation between condition factor and several development in Sardinella aurita (Cuv. \& Val., 1847). Anais Acad. bras. Cienc., 37 (sup1.):353-359.

WATANABE, K. 1963. Variations in chemical composition in some commercial fishes from the south of Brazil. Bull. Jap. Soc. scient. Fish., $29(5): 469-474$.

WEATHERLEY, A. H. 1972. Growth and ecology of fish population. London, Academic Press, p. 75-80.

WOOD, R. J. 1958. Fat cycles of North Sea herring. J. Cons. perm. int. Explor. Mer, 23(3):390-398.

ZIJLSTRA, J. J. 1961. On the recruitment mechanism in the North Sea herring. I. C. E. S. Herring Symposium, Paper no 29 (mimeo).

(Recebido em 29/julho/1975) 